Article

\title{
Application of a Novel Hybrid f-SC Risk Analysis Method in the Paint Industry
}

\author{
Suleyman Enes Hacibektasoglu $1, * \mathbb{D}$, Bulent Mertoglu ${ }^{2}$ and Hakan Tozan ${ }^{3}$ \\ 1 Department of Occupational Safety, Institute of Pured and Applied Sciences, Marmara University, \\ 34722 Istanbul, Turkey \\ 2 Department of Bioengineering, Faculty of Engineering, Marmara University, 34722 Istanbul, Turkey; \\ bulent.mertoglu@marmara.edu.tr \\ 3 Department of Industrial Engineering, Faculty of Engineering and Natural Sciences, Istanbul Medipol \\ University, 34810 Istanbul, Turkey; htozan@medipol.edu.tr \\ * Correspondence: sehacibektasoglu@gmail.com
}

check for updates

Citation: Hacibektasoglu, S.E.; Mertoglu, B.; Tozan, H. Application of a Novel Hybrid f-SC Risk Analysis Method in the Paint Industry. Sustainability 2021, 13, 13605. https://doi.org/10.3390/su132413605

Academic Editor: João Carlos de Oliveira Matias

Received: 10 November 2021 Accepted: 6 December 2021 Published: 9 December 2021

Publisher's Note: MDPI stays neutral with regard to jurisdictional claims in published maps and institutional affiliations.

Copyright: (c) 2021 by the authors. Licensee MDPI, Basel, Switzerland. This article is an open access article distributed under the terms and conditions of the Creative Commons Attribution (CC BY) license (https:/ / creativecommons.org/licenses/by/ $4.0 /)$.

\begin{abstract}
Occupational health and safety (OHS) activities aim to ensure the full mental and physical well-being of employees in the workplace. For this reason, it is essential to determine the precautions to be taken and the suitability of risk assessments. In this study, f-SC, a novel hybrid risk analysis method using Step-Wise Weight Assessment Ratio Analysis (SWARA) and Complex Proportional Assessment (COPRAS) multi-criteria decision making methods (MCDM) based on fuzzy logic, was developed to perform a classical Fine-Kinney risk analysis method. There are few studies in the literature about the Fine-Kinney method compared to other risk analysis methods such as FMEA and FTA. Therefore, this work aimed to integrate this classical method with the proposed method to obtain more accurate and sensitive results in risk analyses. First, the criteria used in determining the risk score were weighted with the help of $10 \mathrm{OHS}$ experts. As the criteria used in the classical method are evaluated with equal importance, this situation can cause serious errors in the risk scores obtained with the relevant calculations and in the risk priorities based on these calculations. We aimed to minimize the occurrence of such errors by determining the weights of the criteria with the proposed method. f-SWARA was used for this process. The weights of probability, exposure, and severity criteria were obtained as $0.196,0.285$, and 0.518 , respectively. Thus, it was determined that severity is an important and effective criterion for calculating the risk score. In the proposed method, after the criterion weights were determined, an analysis of the hazards was conducted with the f-COPRAS method instead of the classical Fine-Kinney method. Contrary to the numerical values used in the classical method, in this method, decision makers use linguistic terms that are more intuitive than numerical values. These linguistic terms were converted into numerical values using this method based on fuzzy logic, and a ranking of hazards was obtained. As a result of the analyses, it was seen that the case study, H7, which had a $0.557 N_{i}$ value, was the most dangerous scenario and that H11, which had a $1.000 N_{i}$ value, was the least dangerous. In addition, for the same data, analyses were conducted using the fuzzy Vise Kriterijumska Optimizacija I Kompromisno Resenje (VIKOR) method, which has been previously used in the literature, and a comparison was made with the f-SC method to demonstrate the validity of the study. The results of the f-VIKOR and classical Fine-Kinney methods were similar to the developed f-SC method. This research provides three contributions: (1) criteria must be weighted to determine risk scores, (2) using intuitive linguistic terms in scoring criteria made the risk analysis method more sensitive and appropriate, and (3) using MCDM methods instead of classical methods for the risk analyses in the OHS field removes uncertainties.
\end{abstract}

Keywords: occupational health and safety; risk assessment; fuzzy logic; f-SWARA; f-COPRAS; f-SC

\section{Introduction}

Despite the developments in technology, new difficulties have arisen in the field of occupational health and safety (OHS). For this reason, various accidents result in the death 
or injury of employees in the workplace [1]. OHS activities include hazards that may arise from processes carried out in the workplace as well as efforts to eliminate risks that may arise as a result of these hazards [2]. Each business can have its own sources of hazards, or hazards can be similar to those of other businesses. Identifying these hazards in risk assessment procedures is one of the most important steps to be carried out in the workplace. Various quantitative and qualitative risk analysis methods are used in the literature for risk assessment.

The most important stage of the risk analysis is the determination of the risk score. Necessary precautions are taken for the related OHS activities, and the time period required for the implementation of these measures is determined according to the obtained risk score. A mistake made at this stage may result in the late implementation of a precautionary measure. This can cause unwanted accidents to occur. For this reason, it is necessary to carefully identify potential hazards and sources of hazards while conducting risk analyses. In addition, the risk analysis used must be quite sensitive [3,4].

Nowadays, the use of multi-criteria decision-making (MCDM) methods has become quite common in decision-making processes. With these methods, the aim is that correct decisions are made from the simplest to the most complex state. In MCDM methods, the most important issue for a decision to be made precisely and accurately is the determination of the criteria. Making a mistake in the setting criteria can lead to irreversible results in the decisions made. There are many MCDM methods that have been used in different studies. In this context, the use of MCDM methods is becoming more widespread in the field of OHS in today's risk analysis [5].

In general, the risk score of the classical risk analysis methods used for risk assessment in the workplace is calculated by the mathematical multiplication of criteria given numerical values. For this reason, this classical approach creates disadvantages and uncertainties. Although the assigned numerical values have meaning, using linguistic terms in assigning the criteria and its alternatives is more intuitive for the decision maker, which will help to remove these disadvantages. Fuzzy logic appears to be a suitable method for this process. After expressing the criteria in terms of definitions, numerating these expressions with the help of fuzzy numbers will give more meaningful results and help to eliminate possible human errors [6].

In decision making analyses, every criterion is evaluated against each other, and these criteria are weighted because the importance level of each criterion is different, just as in classical risk analysis methods. For example, in the classical Fine-Kinney method, the risk score is obtained by multiplying the values of Probability (P), Severity (S), and Exposure (E), which are determined according to a relevant scale. However, in this method, a risk with $\mathrm{P}$, $\mathrm{E}$, and $\mathrm{S}$ values of 6,6 , and 3 , respectively, is prioritized, compared to a risk with values of 1,2 , and 40 . In other words, a situation that will cause a fatal accident or occupational disease in the case of an accident becomes less important than a situation that will result in a simple injury. For this reason, these disadvantages should be eliminated by weighting parameters with the help of decision-making methods.

In this study, a classical Fine-Kinney risk analysis conducted in the paint industry was modeled with a new hybrid MCDM method called f-SC, based on fuzzy logic. First of all, the criteria used in the risk score calculation was weighted with the fuzzy SWARA method by OHS experts. Afterwards, verbal expressions were used instead of the numerical values used in classical methods, and analysis was completed with the help of the fuzzy COPRAS method.

It is mandatory to make risk assessments and employ OHS experts in the workplace in Turkey because of the nation's 2012 enactment of the OHS law, numbered 6331. The using of risk analysis methods increased in workplaces in Turkey because of this. Although a risk analysis conducted for any industry has to be suitable for that industry, many companies use the classical Fine-Kinney method because of its simplicity. However, this method has limitations, e.g., the numerical data given the criteria cause uncertainties when calculating the risk score, and in this method, all the criteria have same weight. Thus, all of them affect 
the risk score evenly. Those can cause major faults when determining precautions according to the risk score. The aims of this paper are to (1) determine the effect of the criteria on the risk score with the f-SWARA method, (2) enable OHS experts to make independent scores, (3) minimize the uncertainties and errors that may arise from the numerical scoring in the classical Fine-Kinney method with the help of linguistic terms, and (4) create hazard clusters sensitively and rank hazards accurately using the fuzzy-based COPRAS method.

To the best of our knowledge, no study has been conducted with the f-SC method in the OHS field for a risk analysis. We want to develop the classical Fine-Kinney risk analysis with an integrated f-SC method because this method is used widely in Turkey in many industries. Different from other studies, we can explain why we developed this method, and our key points are as follows:

$>$ There are a few studies in the literature using AHP for the weighting of the $\mathrm{P}, \mathrm{E}$, and $\mathrm{S}$ criteria for Fine-Kinney risk analysis in OHS, as opposed to other analysis methods such as FTA, FMEA, and HAZOP. We suggest the SWARA method for the criteria weighting process because of some of its advantages. SWARA requires considerably lower pairwise comparisons compared to AHP for the same number of criteria. Thus, SWARA is simpler than AHP $[7,8]$.

$>$ As the number of criteria used in the AHP method increases, the number of comparisons significantly increases. This has a negative impact on comparisons. SWARA is not similar in this regard.

> SWARA, which contains significantly fewer pairwise comparisons than AHP, is an effective method for the use of less prepared participants [7-10].

$>$ There are studies using methods such as TOPSIS and VIKOR for risk analysis in OHS. We suggest the COPRAS method for risk analysis because it is quite simple in terms of use. It does not rely on a high number of long calculations compared to other methods $[10,11]$.

$>$ In the COPRAS method, calculations can be made for criteria to be maximized and minimized, and these criteria are handled and evaluated separately [10-12].

$>$ The COPRAS method shows the degree of the benefit of the alternatives. By comparing the alternatives with each other, we can reveal how good or how bad it is compared to the other alternatives, and this helps to rank all of the alternatives [12].

$>$ The COPRAS method provides an opportunity to evaluate both the qualitative and quantitative criteria [12].

There are many studies that have used MCDM methods in the literature. Lately, some studies using MCDM methods have also applied them to risk analyses in the OHS field. We provide some examples in the following.

Wang and Xie studied the risk of fire occurring on an offshore platform. In this case, a fuzzy-logic-based fault tree method was used. In addition, they proposed a new method by integrating Bayes networks, which is a more comprehensive method than fuzzy logic. In their case study, they stated that fuzzy logic can be integrated directly into Bayes networks, and these networks can be used to predict marginal status. They stated that this integrated method is more flexible and useful than the traditional fault tree analysis method [13]. A study was carried out by Wang et al. in 2013 on oil tank fire and explosions, which occur frequently in refineries and cause life and economic losses and environmental pollution. In this study, the events that caused oil tank explosions were determined, and a fault tree was created. However, a new fuzzy logic-based analysis method was suggested by stating uncertainties existing in the traditional fault tree analysis method due to insufficient data. According to Wang et al., the new system helps to eliminate existing uncertainties [14]. Kou and others conducted a financial risk analysis in 2014. The TOPSIS, DEA, and VIKOR MCDM methods were chosen for that analysis. They proposed this method to rank a selection of popular clustering algorithms in the domain of financial risk analysis. They used a case study to validate their proposed approach. With the obtained results, they saw the effectiveness of MCDM methods in evaluating clustering algorithms [15]. Lui et al. studied decision making mechanisms in relation to emergency responses using a fault tree 
method in 2014. Emergency scenarios were predicted by this method, which was applied to H1N1 disease [16]. Lavasani et al. conducted a risk assessment study in 2015 on the petrochemical industry, where incidents such as fires, explosions, and toxic gas releases have been observed. In their study, the fuzzy logic fault tree method was used. For the quantitative fault tree analysis method, gathering enough data is significant. Therefore, a qualitative solution was quantitated with the help of fuzzy logic [17]. Rajakarunakaran et al. conducted a study on LPG tanks at gas stations in 2015 using the fault tree risk analysis method. The fault tree created in the study was quantitated with data received from experts and then scored with the help of fuzzy logic. They stated that this study contributed to the elimination of uncertainties in that method [18]. Guneri et al. conducted a study to choose the most suitable risk assessment method with a fuzzy-based AHP method for small and medium-sized enterprises (SMEs) in 2015. They chose the Turkish woven-printed-carton labelling company as a case study and determined four criteria: scope, practicality, cost, and sensitivity. They emphasized that decision-making methods can be useful for choosing suitable methods for companies [19]. In 2016, Othman et al. conducted a study to prioritize hazards with the AHP method in HAZOP analysis. The proposed method both prioritizes and quantitatively analyzes hazards. They applied two different case studies to show the efficacy of the proposed method. They emphasized that the proposed method helps to determine and prioritize hazards in the HAZOP method [20]. Dağsuyu et al. conducted a study on existing hazards and the assessment of their risks in sterilization chambers, one of the riskiest places in the health sector, in 2016. The Failure Mode and Effect Analysis method was used. Risk analysis was then modeled with fuzzy logic and presented as a new method. In addition, a $5 \times 5$ method risk analysis was conducted for the same location, and the two methods were compared. In conclusion, they emphasized that the proposed method was more effective than the other method [21]. Gül and Çelik conducted a study in 2017 on railroad transportation, the most important transportation system for crowded metropolises. Fuzzy logic based on the Fine-Kinney risk analysis method was used in their study. The numbers in the classical Fine-Kinney method were replaced with verbal definitions and then quantified with the fuzzy logic method [22]. Muhammet Gül et al. developed a hybrid risk analysis in ballast tanks used in the maritime industry in 2017. The Fine-Kinney risk analysis was modelled using the fuzzy logic method with Analytical Hierarchy Process (AHP) and Vlse Kriterijumska Optimizacija I Kompromisno Resenje (VIKOR) methods for this industry. They stated that the proposed method was useful and practical and stated that it could be adapted to different sectors [3]. Another study was conducted by Ali Kokangül et al. In 2017, the Fine-Kinney risk analysis was modeled using the AHP method to identify and score categorized hazards. The aim of that study was to minimize the interpretation differences in risk analysis [23]. Yazdi and Kabir, in 2017, proposed a method based on the classical fault tree analysis method, which is widely used in risk assessments in process industries. In their study, the fault tree analysis was modelled with fuzzy logic using Bayes networks. They emphasized that classical fault tree analysis has complexity in eliminating uncertainties in hazards and that this new proposed method works better in this regard. In addition, the proposed method was applied to an ethylene production facility as an example [24]. Gül and Ak, in 2018, compared two analysis methods: risk analysis modeled with a $5 \times 5$ matrix using the AHP method with the help of Pythagoras fuzzy clusters and a TOPSIS method via trapeze fuzzy clusters, a multicriteria decision-making method. They obtained similar results from both methods [25]. In 2018, Fattahi and Khalilzadeh developed a new method for a workplace in the steel sector using the Failure Mode and Effect Analysis method used in the risk assessment stage in various industries. They created a hybrid method. In addition to fuzzy logic based on AHP modeling for classical FMEA, they used fuzzy logic based on MULTIMOORA modeling for three parameters: time, cost, and profitability. They evaluated the data obtained by taking the weighted mean of the results of these two analyses [26]. Gul conducted a review study that evaluated 80 different studies based on MCDM risk analysis methods in 2018. He aimed to present these studies to researchers and determine the trend topics 
and methods in the OHS. It was found that many studies use the AHP method with the TOPSIS and VIKOR methods compared to others in the literature [27]. Our study will contribute to the literature because it is a novel hybrid method. Markowski and Siuta studied representative accident scenarios (RASs) with both traditional HAZOP and its fuzzy-based version. A liquefied natural gas (LNG) storing facility was used as the case study. They used the efficacy index (EI) and quality index (QI) to develop the risk correction index (RCI), which was used to determine the accident scenarios. They found that the fuzzy-based method was more sensitive than the traditional method. Moreover, they mentioned that the fuzzy-based method has some advantages compared to the traditional method [28]. Chen et al. conducted a case study to reduce risk levels at the Oilfield Gathering Station (OGS) integrating AHP and fuzzy comprehensive evaluation (FCE) in 2019. An evaluation index system of safety performance at the OGS was established, and it included a tank unit index, pipe unit index, digital monitoring unit index, and other systems. Each index was weighted with the AHP method. Combining the AHP and the FCE methods, the risk levels of representative enterprise $S$ were validated. They found that the grade of S-OGS was low-risk. They emphasized that the study helped to improve the risk levels of the OGS [29]. In 2020, Simic et al. conducted a fuzzy-MCDM-based risk analysis study on railway infrastructure. They used fuzzy sets for express information about risks, and, with the help of Tsallis-Havrda-Charvát entropy, a hybrid method was conducted. Subsequently, fuzzy measurements of alternatives and a compromise solution method were developed to rank railway infrastructures. They demonstrated the substantiality of the proposed approach with sensitivity analyses [30]. In 2020, Marhavilas et al. developed a new risk analysis method with the joint collaboration of a deterministic (DET) and a stochastic (STO) process named MCDM-STO/DET for sustainable engineering projects. They used real work accident data from between 2009 and 2016 taken from "SEPE" (Labor Inspectorate, Hellenic Ministry of Employment) and "IKA" (Social Insurance Institution, Hellenic Ministry of Health). They chose the Greek construction sector and the fixed telecommunications technical projects of OTE SA (that is, the Greek Telecommunications Organization S.A.) as a case study. They aimed to help upgrade the OHS field and the sustainability of engineering projects with that study [31]. Marhavilas et al. proposed the HAZOP method integrated with a Decision Risk-Matrix (DRMA) and fuzzy-based AHP (f-AHP) to determine potential hazards in a crude-oil processing plant in Greece in 2020. They aimed to develop and generalize this method in that industry. The classical HAZOP was used to identify fault causes in abnormal circumstances, and DRMA was used for an assessment of the risks. Subsequently, f-AHP was used to extend the study and prioritize the hazards [32]. Marhavilas et al. conducted a HAZOP risk analysis integrated with classical and fuzzy-based AHP focused on the economic, health, and environmental impact of the sour-crude-oil process industry in 2020. They aimed to show the applicability of the classical HAZOP method and the usability of hazard analysis with the proposed integrated method arising from economic, health, and environmental circumstances. They also aimed to determine the potential destructive hazards with the classical HAZOP in abnormal circumstances in related industries. They emphasized that this proposed method helps to improve OHS levels and has certain advantages for decision makers [33]. In 2021, Shahri et al. studied the FMEA risk analysis method. They proposed the PFVIKOR method, a Pythagorean fuzzy-based MCDM method, for a dehydration unit of an Iranian gas refinery. In that study, they first used Pythagorean fuzzy numbers to collect criteria: Severity (S), Occurrence (O), and Detection (D). Afterward, they used the k-means clustering algorithm to cluster failure modes, which was a novel method accepting PFNs as input. Finally, they used the PF-VIKOR approach to analyze the ordering of cluster risks. They compared the results with the classical FMEA method [34]. Boral and Chakraborty applied a MCDM-based risk analysis method for CNC machines in 2021. FMEA was chosen for the risk analysis in that study. They evaluated the failures of the CNC machines caused by human error. First, they identified major human errors with the FMEA method during the CNC machining process, which was performed by the experts. Afterwards, a fuzzy- 
based method, i.e., an interval type-2 fuzzy set (IT2FS) MCDM framework, was developed for prioritizing risks. In this process, they used the AHP, DEMATEL, and MARCOS as MCDM methods. Finally, they ranked the risks and compared these three fuzzy-based methods [35]. In 2021, Tabatabaeea and others developed a fuzzy-based MCDM method for identifying and evaluating risk factors for Building Information Modelling (BIM)-based industralised building system (IBS) projects. They used the Fuzzy Delphi Method to identify and determine risk factors. Afterwards, they performed the analyses with the help of DEMATEL and the Parsimonious-Fuzzy Analytic Network Process. The method allowed users to prioritize risk factors with an understandable procedure [36]. Wang et al. conducted a study to develop a new FMEA method combined with fuzzy-based MCDM methods. They aimed to eliminate the shortcomings of classical FMEA. For this reason, the risk factors were weighted as subjective and objective with social network analysis and the maximizing consensus method. The weights of these factors were integrated with the TOPSIS MCDM method to obtain an ideal solution. Finally, they made a case study to show the effectiveness of the proposed method [37].

\section{Research Methodologies}

Within the scope of this study, a risk analysis conducted with the classical Fine-Kinney method in a workplace in the paint industry was modeled by a new hybrid method called the f-SC risk analysis method. For this purpose, the criteria used in risk score evaluation were first weighted with fuzzy logic based on the SWARA method, and the analysis was then completed using fuzzy logic based on the COPRAS method. Moreover, the f-VIKOR method used for risk analysis in the field of OHS in the literature was applied to determine the differences between these methods.

\subsection{Classical Fine-Kinney Risk Analysis Method}

The Fine-Kinney risk analysis method is a quantitative method developed in 1976 in order to control hazards. This classical method includes 3 criteria: Probability $(\mathrm{P})$, Exposure (E), and Severity (S) [38].

Probability (P)

Although probability values should be in the range of $0-1$ mathematically, a different scale was developed for probability, similar to other factors in the Fine-Kinney method. In this scale, the probability of occurrence in the workplace is evaluated between "might well be expected" and "virtually impossible" risks [3,22,38].

Exposure (E)

An exposure-oriented scale was determined for the exposure value. This scale ranges from continuous exposure to very rare, which is an annual exposure $[3,22,38]$.

Severity (S)

A classification was made for an accident that may occur; the severity value is determined according to the predicted injury or death status and accordingly the financial loss table that will arise $[3,22,38]$.

Risk Score (RS)

In the classical Fine-Kinney method, the risk score is determined by the multiplication of probability, severity, and exposure values. For these determined risk scores, there are five different risk situations and a priority of precautions $[3,22,38]$.

\subsection{Fuzzy Set Theory}

The fuzzy set theory was developed by Zadeh to overcome the uncertainties of problems that can occur. In this method, problems are examined with the help of linguistic terms. These linguistic terms are then converted into fuzzy numbers with the help of decision makers. Triangular fuzzy numbers are shown as $\mathrm{A}=(l, m, u)$. Here, "l" indicates the lowest, " $m$ " is the medium, and " $u$ " is the highest value, respectively. Triangular fuzzy numbers are shown in Figure 1 [22,39]. 


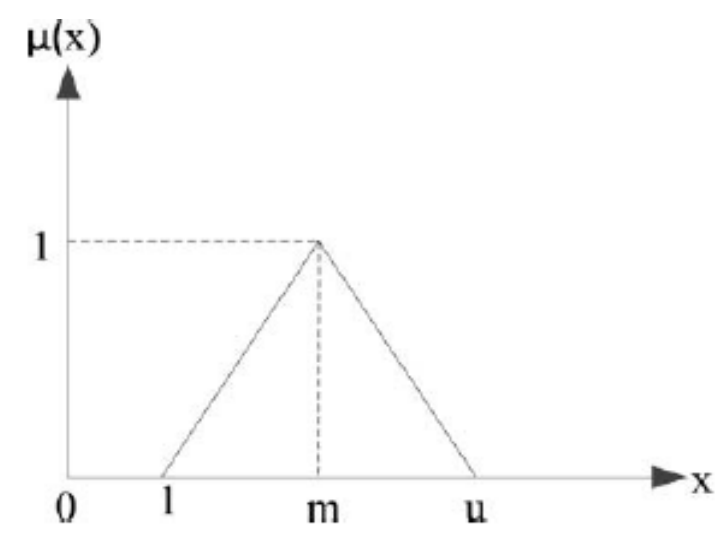

Figure 1. Triangular fuzzy numbers.

Membership functions of triangular fuzzy numbers are shown in Equation (2).

$$
\mu \widetilde{A}=\left\{\begin{array}{cc}
0, & x<l \\
\frac{(x-l)}{(m-l)}, & l \leq x \leq m \\
\frac{(u-x)}{(u-m)}, & m \leq x \leq u \\
0 & x \geq u
\end{array}\right.
$$

The mathematical operations $\left(\widetilde{A}_{1}=\left(l_{1} m_{1} u_{1}\right)\right.$ ve $\left.\widetilde{A}_{2}=\left(l_{2} m_{2} u_{2}\right)\right)$ of any two triangular fuzzy numbers are shown in Table 1.

Table 1. Arithmetic operations of triangular fuzzy numbers.

\begin{tabular}{lc}
\hline Addition & $\widetilde{A}_{1}+\widetilde{A}_{2}=\left(l_{1}+l_{2}, m_{1}+m_{2}, u_{1}+u_{2}\right)$ \\
Subtraction & $\widetilde{A}_{1}-\widetilde{A}_{2}=\left(l_{1}-u_{2}, m_{1}-m_{2}, u_{1}-l_{2}\right)$ \\
Multiplication & $\widetilde{A}_{1} \times \widetilde{A}_{2}=\left(l_{1} \times l_{2}, m_{1} \times m_{2}, u_{1} \times u_{2}\right)$ \\
Division & $\widetilde{A}_{1} / \widetilde{A}_{2}=\left(l_{1} / u_{2}, m_{1} / m_{2}, u_{1} / l_{2}\right)$ \\
\hline
\end{tabular}

\subsection{SWARA Method}

The SWARA method was developed in 2010 by Kersuliene et al. Today, the use of this MCDM method is becoming increasingly widespread. In this method, the role of decision makers is vital compared to others. This method provides for the opportunity to choose one's own priorities for the determined criteria for decision makers $[8,10]$.

\subsection{COPRAS Method}

The COPRAS (COmplex PRoportional ASsesment) method was developed in 1996 by Zavadskas and Kaklauskas. In this method, alternatives are ranked according to their importance and benefit values. While making an alternative assessment, the method aims to maximize beneficial values and minimize useless ones. This process is based on the importance of the decision options and the direct and proportional dependence of priority. In 2007, the fuzzy COPRAS method was developed by Zavadskas and Antucheviciene. This method was used to determine alternative decisions for the renewal of abandoned buildings in the rural areas of Lithuania [11].

In the classical COPRAS method, scoring is made by giving numerical values for alternatives. This situation may cause uncertainties and inadequacies in the analyses. For this reason, when scoring, it is more appropriate to use intuitive linguistic terms.

\subsection{A Novel Hybrid f-SC Risk Analysis Method}

Classical risk analysis methods used in workplaces assume that the weights of all criteria are equal. However, it is not possible for all criteria to have equal importance. For this reason, the criteria must be weighted with the help of expert decision makers. In 
this study, a Fine-Kinney risk analysis was conducted with the new hybrid f-SC method containing two MCDM methods: SWARA and COPRAS. SWARA was integrated with COPRAS since there is no criterion weighting in the COPRAS method. After determining the criterion weights with SWARA, a risk analysis was conducted with classical Fine-Kinney and modeled by COPRAS, and an alternative list for hazards was created. In this modeling, both SWARA and COPRAS methods were implemented based on fuzzy logic. In this way, the criteria of hazards were quantified with the help of fuzzy logic. In Figure 2, the stages of the f-SC risk analysis method are given.

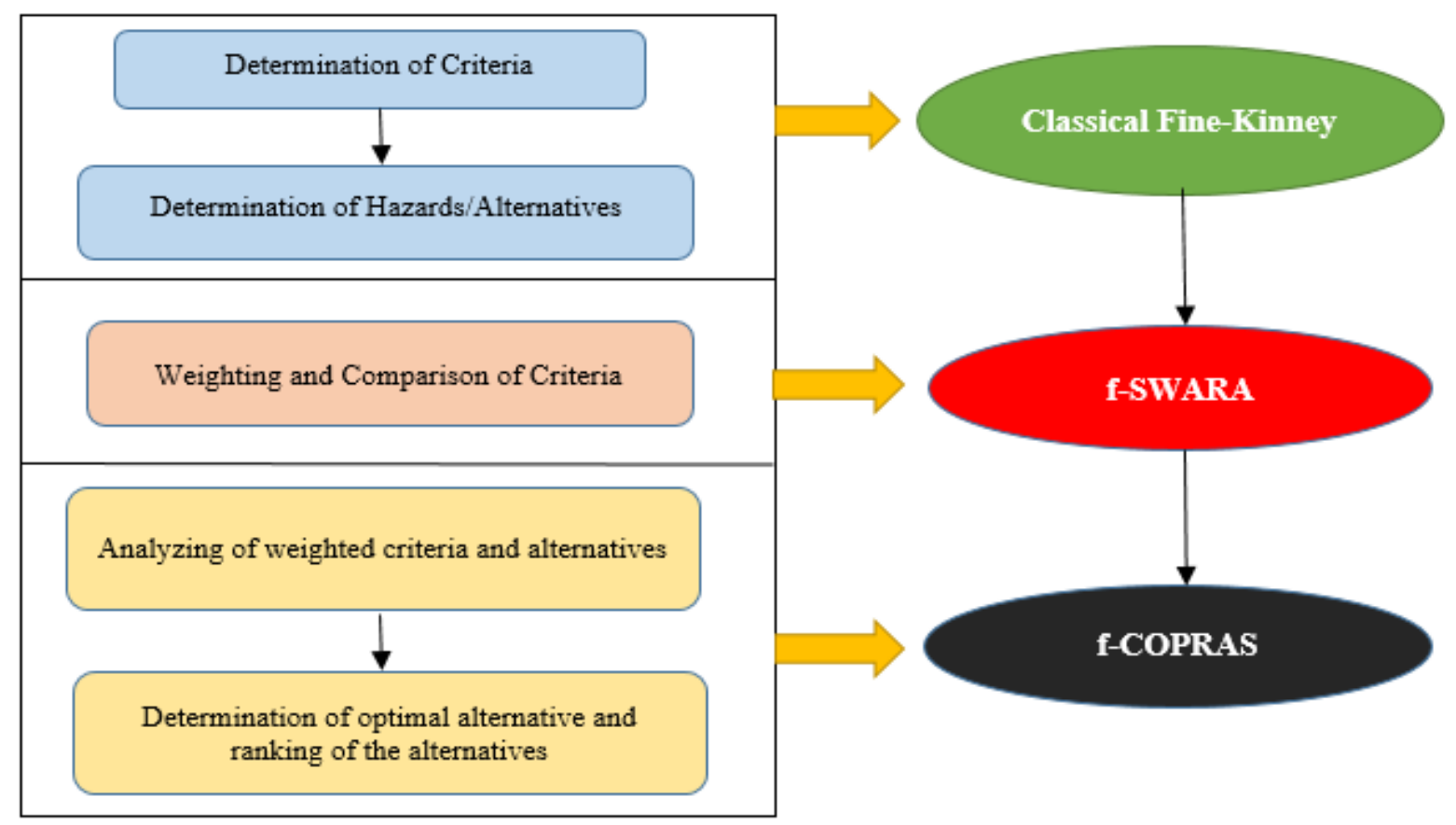

Figure 2. Scheme of the novel hybrid f-SC method.

Our novel hybrid method consists of three main stages as seen in Figure 2. The steps of this method are as follows.

1st Stage: Determination of Criteria (Classical Fine-Kinney method)

The classical Fine-Kinney method was used for determining the criteria for this study. In this method, the risk score (RS) is evaluated by multiplying Probability, Exposure, and Severity values $[23,38]$ :

$$
R S=P x E x S
$$

In the Fine-Kinney method, separate tables have been defined by Kinney to determine Probability (P), Severity (S), and Exposure (E) values. The risk score is calculated by determining the numerical values corresponding to the statements in these tables separately for each parameter [38].

Probability, Exposure, and Severity values and the different risk situations arising from the Risk Score are shown in Table 2. 
Table 2. P, E, S, and RS values $[3,22,23,38]$.

\begin{tabular}{|c|c|c|c|}
\hline Likelihood & Value & Exposure Factor & Value \\
\hline Might well be expected & 10 & Continuous & 10 \\
\hline Quite possible & 6 & Frequent (daily) & 6 \\
\hline Unusual but possible & 3 & Occasional (weekly) & 3 \\
\hline Only remotely possible & 1 & Unusual (monthly) & 2 \\
\hline Conceivable but very unlikely & 0.5 & Rare (a few per year) & 1 \\
\hline Practically impossible & 0.2 & Very rare (yearly) & 0.5 \\
\hline Virtually impossible & 0.1 & & \\
\hline Possible Severity & Value & & \\
\hline $\begin{array}{l}\text { Catastrophe } \\
\text { (many fatalities, or }>\$ 10^{7} \\
\text { damage) }\end{array}$ & 100 & Risk Score & Risk Situation \\
\hline $\begin{array}{l}\text { Disaster } \\
\text { (few fatalities, or } \\
>\$ 10^{6} \text { damage) }\end{array}$ & 40 & $>400$ & $\begin{array}{l}\text { Very high risk; consider } \\
\text { discontinuing operation }\end{array}$ \\
\hline $\begin{array}{l}\text { Very serious } \\
\text { (fatality, or } \\
>\$ 10^{5} \text { damage) }\end{array}$ & 15 & 200 to 400 & $\begin{array}{l}\text { High risk; } \\
\text { immediate correction required }\end{array}$ \\
\hline $\begin{array}{l}\text { Serious } \\
\text { (serious injury, or } \\
\$ 10^{4} \text { damage) }\end{array}$ & 7 & 70 to 200 & Substantial risk; correction needed \\
\hline $\begin{array}{l}\text { Important } \\
\text { (disability, or } \\
\$ 10^{3} \text { damage) }\end{array}$ & 3 & 20 to 70 & $\begin{array}{l}\text { Possible risk; } \\
\text { attention indicated }\end{array}$ \\
\hline $\begin{array}{l}\text { Noticeable } \\
\text { (minor first aid accident, or } \\
>\$ 100 \text { damage) }\end{array}$ & 1 & $<20$ & $\begin{array}{l}\text { Risk; } \\
\text { perhaps acceptable }\end{array}$ \\
\hline
\end{tabular}

2nd Stage: Weighting and Comparison of the Criteria (f-SWARA method)

The f-SWARA method was used for the weighting of the criteria $(P, E$, and $S)$. The steps of the SWARA method are as follows $[9,10]$.

1st Step: Criteria are ranked from high to low according to the opinions of the decision makers. If there are multiple decision-makers, the ranking is made separately and a general ranking is determined by taking the geometric mean.

2nd Step: The relative significance of each criterion is determined. For comparing the $\mathrm{j}$ criterion with the $(j+1)$ criterion, how important the $\mathrm{j}$ criterion is in relation to the $(j+1)$ criterion is determined. This value $\left(s_{j}\right)$ is called the "comparative significance of the mean value".

3rd Step: The $k_{j}$ coefficient is determined:

$$
k_{j}=\left\{\begin{array}{cc}
1 & j=1 \\
s_{j+1} & j>1
\end{array}\right\}
$$

4th Step: The $q_{j}$ variable is determined:

$$
q_{j}=\left\{\begin{array}{cc}
1 & j=1 \\
\frac{q_{j-1}}{k_{j}} & j>1
\end{array}\right\}
$$


5th Step: The relative weights of the evaluation criteria are determined as follows, where $w_{j}$ refers to the relative weight of the $j$ criterion:

$$
w_{j}=\frac{q_{j}}{\sum_{k=1}^{n} q_{k}}
$$

In this study, the SWARA method was based on fuzzy logic. For this reason, decision makers expressed the importance of the criteria using the terms in Table 3. Afterwards, defuzzification was performed using fuzzy numbers corresponding to the linguistic terms.

Table 3. Linguistic terms for the fuzzy weighting criterion.

\begin{tabular}{lc}
\hline Linguistic Terms & Fuzzy Numbers \\
\hline None (N) & $(1,1,2)$ \\
Very Low (VL) & $(1,2,3)$ \\
Low (L) & $(2,3,4)$ \\
Fairly Low (FL) & $(3,4,5)$ \\
Medium (M) & $(4,5,6)$ \\
Fairly High (FH) & $(5,6,7)$ \\
High (H) & $(6,7,8)$ \\
Very High (VH) & $(7,8,9)$ \\
\hline
\end{tabular}

3rd Stage: Analysis of the weighted criteria and hazards/alternatives (f-COPRAS method).

In the fuzzy COPRAS method, alternatives are evaluated via linguistic terms by decision makers and quantified with the help of fuzzy logic. In this way, uncertainties disappear [11]. The steps of this method are as follows.

1st Step: Definition of the linguistic terms. In this step, alternatives are determined based on fuzzy logic with linguistic terms according to the criteria. Linguistic terms based on fuzzy logic are shown in Table 4.

Table 4. Linguistic terms for the hazards/alternatives.

\begin{tabular}{lc}
\hline Linguistic Terms & Fuzzy Numbers \\
\hline Very poor (VP) & $(0,0,1)$ \\
Poor (P) & $(0,1,3)$ \\
Medium poor (MP) & $(1,3,5)$ \\
Fair (F) & $(3,5,7)$ \\
Medium good (MG) & $(5,7,9)$ \\
Good (G) & $(7,9,10)$ \\
Very good (VG) & $(9,10,10)$ \\
\hline
\end{tabular}

2nd Step: Creation of the fuzzy decision matrix. Here, a fuzzy-based matrix with $\mathrm{n}$ criteria and $\mathrm{m}$ alternatives is created. This matrix, shown in Equation (6), is created by decision makers.

$$
\widetilde{D}=\left[\begin{array}{cccc}
x_{11} & x_{12} & \cdots & x_{1 n} \\
x_{21} & x_{22} & \cdots & x_{2 n} \\
\vdots & \vdots & \cdots & \vdots \\
x_{m 1} & x_{m 2} & \cdots & x_{m n}
\end{array}\right]
$$

3rd Step: Defuzzification of the fuzzy decision matrix. The graded mean integration representation method was used for the defuzzification of the fuzzy decision matrix. This method is simple and useful [40]. The best non-fuzzy performance value for the fuzzy number $\widetilde{A}=\left(l_{i}, m_{i}, u_{i}\right)$ is calculated as follows:

$$
B N P_{i}=\frac{l_{i}+4 \times m_{i}+u_{i}}{6}
$$


4th Step: Normalization of the defuzzified decision matrix. The normalized value of this matrix is calculated with " $w$ " data integrated into this equation with the help of f-SWARA (Equation (5)), as follows:

$$
\overline{x_{i j}}=\frac{w \times x_{i j}}{\sum_{j=1}^{n} x_{i j}}, \quad i=1, m ; j=1, n .
$$

After the calculation, the decision matrix is normalized as follows:

$$
\bar{X}=\left[\begin{array}{cccc}
\bar{x}_{11} & \bar{x}_{12} & \cdots & \bar{x}_{1 m} \\
\bar{x}_{12} & \bar{x}_{22} & \cdots & \bar{x}_{2 m} \\
\vdots & \vdots & \cdots & \vdots \\
\bar{x}_{n 1} & \bar{x}_{n 2} & \cdots & \bar{x}_{n m}
\end{array}\right]
$$

5th Step: Calculation of the weighted normalized decision matrix. Weighted normalized values are calculated as follows:

$$
\hat{x}_{i j}=\bar{x}_{i j} \times q_{j}, \quad i=1, m ; j=1, n \text {. }
$$

After this process, the weighted normalized decision matrix is as follows:

$$
\hat{X}=\left[\begin{array}{cccc}
\hat{x}_{11} & \hat{x}_{12} & \cdots & \hat{x}_{1 m} \\
\hat{x}_{12} & \hat{x}_{22} & \cdots & \hat{x}_{2 m} \\
\vdots & \vdots & \cdots & \vdots \\
\hat{x}_{n 1} & \hat{x}_{n 2} & \cdots & \hat{x}_{n m}
\end{array}\right] ; i=1, m ; j=1, n
$$

6th Step: For each alternative, the sum of the attribute values $\left(P_{i}\right)$ where large values are preferred is calculated:

$$
P_{i}=\sum_{j=1}^{k} \hat{x}_{i j}
$$

Here, $k$ is the attribute value that needs to be maximized.

7th Step: For each alternative, the sum $\left(R_{i}\right)$ of the attribute values in which small values are preferred is calculated:

$$
R_{i}=\sum_{j=k+1}^{m} \hat{x}_{i j}
$$

Here, $(m-k)$ is the attribute value that needs to be minimized.

8th Step: The minimum $R_{i}$ value is determined:

$$
R_{\min }=\min R_{i} ; i=1, n
$$

9th Step: The relative weight of each alternative is calculated:

$$
Q_{i}=P_{i}+\frac{R_{\min } \sum_{i=1}^{n} R_{i}}{R_{i} \sum_{i=1}^{n} \frac{R_{\min }}{R_{i}}}, \quad i=1, m ; j=1, n
$$

10th Step: $K$, the optimality criterion, is determined:

$$
K=\max Q_{i} ; i=1, n
$$


11th Step: Determination of the priority of the project. The alternative with the highest value is the best option for the project.

$$
N_{i}=\left(\frac{Q_{i}}{Q_{\max }}\right) \times 100 \%
$$

With this proposed method, we developed the classical Fine-Kinney method using the f-SWARA and f-COPRAS MCDM methods. We basically used the same equation (Equation (1)). First, the criteria of this equation (P, E, and S) were weighted using Equations (3)-(5) by 10 OHS experts. During the weighting process, all experts were asked to rank the criteria from effective to ineffective according to the f-SWARA method and to express the degree of the influence of each criterion in linguistic terms. All the experts who gave scores ranked the effect of the criteria identically. The criteria are listed from the most effective to the least effective in terms of severity, exposure, and probability. Table 5 contains the expressions used by the experts regarding the level of the influence for each criterion according to the linguistic terms in Table 3. Here, the effect of the severity (at the top) on the exposure and the effect of the exposure on the probability (at the bottom) are evaluated. Since there are no criteria on the effect on severity, there are no input values for this criteria's row. The criteria weighting calculations of the 1st decision maker are given in Table 6 as an example. Decision makers performed this process independently of one other. Afterwards, the geometric mean of the experts' data was used as the final value for the weighting value $(w)$.

Table 5. Expression of the criteria in linguistic terms according to f-SWARA by OHS experts.

\begin{tabular}{|c|c|c|c|c|c|c|c|c|c|c|}
\hline \multirow{2}{*}{ Criteria } & \multicolumn{10}{|c|}{ Decision Makers } \\
\hline & DM1 & DM2 & DM3 & DM4 & DM5 & DM6 & DM7 & DM8 & DM9 & DM10 \\
\hline Severity & - & - & - & - & - & - & - & - & - & - \\
\hline Exposure & $\mathrm{H}$ & $\mathrm{H}$ & $\mathrm{H}$ & $\mathrm{FH}$ & $\mathrm{FH}$ & $\mathrm{H}$ & $\mathrm{FH}$ & $\mathrm{VH}$ & $\mathrm{H}$ & M \\
\hline Probability & $\mathrm{FH}$ & M & FH & $\mathrm{H}$ & $\mathrm{N}$ & FL & VL & $\mathrm{L}$ & $\mathrm{N}$ & $\mathrm{L}$ \\
\hline
\end{tabular}

Table 6. Weighted criteria calculations of Decision Maker 1.

\begin{tabular}{cccccccccc}
\hline Criteria & $\begin{array}{c}\text { Order of } \\
\text { Importance }\end{array}$ & \multicolumn{2}{c}{ Ordered Criteria } & $\boldsymbol{s}_{j}$ & $\boldsymbol{k}_{j}$ & $\boldsymbol{q}_{j}$ & $\boldsymbol{w}_{j}$ & $\boldsymbol{W}_{j}$ \\
\hline Probability & 3 & $\mathrm{~S}$ & 1 & - & - & $(1.000,1.000,1.000)$ & $(1.000,1.000,1.000)$ & $(0.520,0.544,0.566)$ & 0.544 \\
Severity & 1 & $\mathrm{E}$ & 2 & $\mathrm{H}$ & $(6,7,8)$ & $(1.750,1.875,2.000)$ & $(0.500,0.533,0.571)$ & $(0.260,0.290,0.323)$ & 0.291 \\
Exposure & 2 & $\mathrm{P}$ & 3 & $\mathrm{FH}$ & $(5,6,7)$ & $(1.625,1.750,1.875)$ & $(0.267,0.305,0.352)$ & $(0.139,0.166,0.199)$ & 0.167 \\
\hline
\end{tabular}

After the weighting calculations for the criteria were determined by the decision makers with the help of Equations (3)-(5), the final weighting process was performed by taking the geometric mean of all values. The criterion weight values of all decision makers and the final values found with the geometric mean are shown in Table 7.

While evaluating the criteria, all decision makers chose the severity criterion as the most significant criterion with a common decision. By calculating the geometric mean of the values obtained as a result of the calculations made separately for each decision maker, the importance weights of the severity, exposure, and probability criteria were obtained as $0.518,0.285$, and 0.196 , respectively. These obtained values were integrated into the f-COPRAS method, and the relevant weight ratio for each criterion was taken into account.

Subsequently, with the help of the f-COPRAS method, the hazards identified by the experts as suitable for the ISO 31000:2018 Risk Management Guidelines and the Risk Assessment for OHS Regulations depending on the OHS law in Turkey were scored using the data in Table 4, which contains the linguistic terms for valuing the decision matrix by the OHS experts. After this step, " $w$ " data calculated by f-SWARA were integrated into f-COPRAS when normalizing the decision matrix with the equation $\overline{x_{i j}}=\frac{w \times x_{i j}}{\sum_{j=1}^{n} x_{i j}}$. Finally, 
using equations (Equations (9)-(17)) of the f-COPRAS method, $N_{i}$ values of each hazards were determined and ranked from low to high.

Table 7. Weighted criteria according to the f-SWARA method by the decision makers.

\begin{tabular}{cccc}
\hline \multirow{2}{*}{ Decision Makers } & \multicolumn{3}{c}{ Weighted Criteria } \\
\cline { 2 - 4 } & Probability & Exposure & Severity \\
\hline DM1 & 0.167 & 0.291 & 0.544 \\
DM2 & 0.177 & 0.287 & 0.537 \\
DM3 & 0.167 & 0.291 & 0.544 \\
DM4 & 0.163 & 0.305 & 0.533 \\
DM5 & 0.242 & 0.277 & 0.483 \\
DM6 & 0.190 & 0.283 & 0.529 \\
DM7 & 0.228 & 0.282 & 0.492 \\
DM8 & 0.197 & 0.269 & 0.536 \\
DM9 & 0.234 & 0.267 & 0.500 \\
DM10 & 0.219 & 0.299 & 0.484 \\
Geometric Mean & 0.196 & 0.285 & 0.518 \\
\hline
\end{tabular}

According to the ISO 31000:2018 Risk Management Guidelines, "The purpose of risk identification is to find, recognize and describe risks that might help or prevent an organization [from] achieving its objectives. Relevant, appropriate and up-to-date information is important in identifying risks." Due to this, identifying hazards and risks is significant in the workplace. The risk identification process is made according to the risk score in the classical Fine-Kinney method. Using numbers in this method causes problems and uncertainties. The proposed model, which was developed according to IEC 31010:2019 Risk Management—Risk Assessment Techniques, helped to eliminate these shortcomings. In this method, decision makers used the intuitive linguistic terms instead of numbers. Figure 2 shows the stages of our proposed method corresponding to the relevant standards and regulations.

\section{A Case Study for the f-SC Method in the Paint Industry}

In this chapter, a Fine-Kinney risk analysis is implemented with the new hybrid f-SC method in one of the major businesses in the paint industry in Turkey. The paint industry is one of the sectors where chemicals are used extensively. For this reason, the measures taken in paint-related workplaces are classified as very dangerous and are essential in terms of the OHS. Therefore, necessary measures to prevent hazards or to minimize damage were proposed as a result of this risk analysis conducted with the new method. The facility where the application was conducted is very large, so the scope of this study was limited to the water-based paint production section and the area where the silos are located. In this context, 42 hazards were determined for this area.

In the conducted case study, first, the probability, exposure, and severity values determined by the classical Fine-Kinney method were expressed with linguistic terms by 10 decision makers who served as safety experts. In Table 8, the classical risk analysis conducted according to Equation (2) is given. The alternatives expressed with linguistic terms by the decision makers according to Table 4 are shown in Table 9 for the f-SC approach. 
Table 8. Classical Fine-Kinney risk analysis performed for the workplace covered by the study.

\begin{tabular}{|c|c|c|c|c|c|c|c|}
\hline \multirow{2}{*}{$\begin{array}{l}\text { Hazard } \\
\text { Number }\end{array}$} & \multirow{2}{*}{ Hazards } & \multirow{2}{*}{$\begin{array}{c}\text { Potential Impact of } \\
\text { the Hazard }\end{array}$} & \multicolumn{3}{|c|}{ Classical Fine-Kinney Risk Analysis } & \multirow{2}{*}{ Risk Score } & \multirow{2}{*}{$\begin{array}{l}\text { Ranking } \\
\text { Number }\end{array}$} \\
\hline & & & Probability & Exposure & Severity & & \\
\hline H1 & $\begin{array}{l}\text { Loading vehicle crashing into } \\
\text { pedestrians or equipment }\end{array}$ & Death, trauma, injury & 3 & 3 & 40 & 360 & 21 \\
\hline $\mathrm{H} 2$ & $\begin{array}{l}\text { Hitting the employee as a result of the } \\
\text { broken connections between the silo and } \\
\text { the vehicle }\end{array}$ & $\begin{array}{l}\text { Broken bones, crushed } \\
\text { limbs, injury }\end{array}$ & 3 & 3 & 40 & 360 & 21 \\
\hline $\mathrm{H} 3$ & Load lifting, carrying & $\begin{array}{c}\text { Backache, musculoskeletal } \\
\text { disorder }\end{array}$ & 1 & 3 & 7 & 21 & 38 \\
\hline $\mathrm{H} 4$ & Chemical powder exposure & $\begin{array}{l}\text { Eye, skin, or respiratory } \\
\text { system irritation }\end{array}$ & 1 & 6 & 7 & 42 & 35 \\
\hline H5 & $\begin{array}{l}\text { Connection failure due to pressurized } \\
\text { equipment pressure }\end{array}$ & Injury & 1 & 6 & 15 & 90 & 31 \\
\hline H6 & $\begin{array}{l}\text { Using pressure equipment with } \\
\text { malfunctioning pressure gauges }\end{array}$ & Injury, burns & 0.5 & 1 & 40 & 20 & 40 \\
\hline $\mathrm{H} 7$ & $\begin{array}{l}\text { Unsuitable employee working at a } \\
\text { height and their falling from a height }\end{array}$ & Death, broken bones, injury & 6 & 6 & 40 & 1440 & 1 \\
\hline H8 & $\begin{array}{l}\text { Falling from a height during sampling } \\
\text { in silos }\end{array}$ & Death, broken bones, injury & 3 & 6 & 40 & 720 & 7 \\
\hline H9 & $\begin{array}{l}\text { The noise of the raw material silo motor } \\
\text { and pneumatic pumps }\end{array}$ & $\begin{array}{l}\text { Hearing loss, } \\
\text { occupational disease }\end{array}$ & 1 & 3 & 40 & 120 & 29 \\
\hline H10 & Liquid chemical exposure & Eye irritation, defects of vision & 6 & 6 & 7 & 252 & 27 \\
\hline H11 & $\begin{array}{l}\text { Dust emission and chemical contact as a } \\
\text { result of puncture and damage to the } \\
\text { filters on the upper points of the silos }\end{array}$ & $\begin{array}{l}\text { Eye, skin, or respiratory } \\
\text { system irritation }\end{array}$ & 3 & 1 & 7 & 21 & 38 \\
\hline H12 & Vehicle rollover & Limb loss, broken bones, death & 1 & 1 & 40 & 40 & 36 \\
\hline H13 & $\begin{array}{l}\text { Separating of the silobas } \\
\text { monoblock body }\end{array}$ & Death, injury & 1 & 1 & 40 & 40 & 36 \\
\hline H14 & $\begin{array}{l}\text { Failure or explosion of diesel or the } \\
\text { electric motor's compressor in the silo }\end{array}$ & Death, injury & 1 & 0.5 & 40 & 20 & 40 \\
\hline H15 & Crashing vehicles and heavy traffic & Injury, broken bones & 3 & 6 & 15 & 270 & 25 \\
\hline H16 & Statical electricity & Injury, burns & 0.5 & 6 & 40 & 120 & 29 \\
\hline H17 & Exposure to exhaust gas & Respiratory illness & 1 & 3 & 15 & 45 & 34 \\
\hline $\mathrm{H} 18$ & $\begin{array}{l}\text { Not using personal } \\
\text { protective equipment }\end{array}$ & Occupational disease, injury & 3 & 6 & 40 & 720 & 7 \\
\hline H19 & Working with chemicals & Occupational disease, injury & 3 & 6 & 40 & 720 & 7 \\
\hline $\mathrm{H} 20$ & Unfavorable thermal conditions & $\begin{array}{l}\text { Skin irritation, respiratory } \\
\text { system illness }\end{array}$ & 1 & 6 & 15 & 90 & 31 \\
\hline $\mathrm{H} 21$ & $\begin{array}{l}\text { Material falling from the roof or top of } \\
\text { the silos }\end{array}$ & Injury, death & 0.5 & 1 & 40 & 20 & 40 \\
\hline $\mathrm{H} 22$ & $\begin{array}{c}\text { Bringing chemical materials to a } \\
\text { defined area }\end{array}$ & $\begin{array}{l}\text { Backache, musculoskeletal } \\
\text { disorder }\end{array}$ & 3 & 10 & 15 & 450 & 15 \\
\hline $\mathrm{H} 23$ & $\begin{array}{l}\text { Bringing the empty boiler from the } \\
\text { boiler room to the defined area } \\
\text { (10 m distance) }\end{array}$ & $\begin{array}{l}\text { Backache, musculoskeletal } \\
\text { disorder }\end{array}$ & 3 & 10 & 15 & 450 & 15 \\
\hline $\mathrm{H} 24$ & $\begin{array}{l}\text { Transferring chemical materials into } \\
\text { empty boiler }\end{array}$ & $\begin{array}{l}\text { Eye, skin, or respiratory system } \\
\text { irritation, occupational disease }\end{array}$ & 3 & 10 & 15 & 450 & 15 \\
\hline $\mathrm{H} 25$ & $\begin{array}{l}\text { Exposure to liquid and gaseous } \\
\text { raw materials }\end{array}$ & $\begin{array}{l}\text { Eye, skin, or respiratory system } \\
\text { irritation, occupational disease }\end{array}$ & 3 & 10 & 15 & 450 & 15 \\
\hline $\mathrm{H} 26$ & Exposure to powdered raw materials & $\begin{array}{l}\text { Eye, skin, or respiratory system } \\
\text { irritation, occupational disease }\end{array}$ & 3 & 10 & 40 & 1200 & 2 \\
\hline $\mathrm{H} 27$ & Weighing chemicals with a balance & $\begin{array}{l}\text { Backache, musculoskeletal } \\
\text { disorder }\end{array}$ & 3 & 10 & 15 & 450 & 15 \\
\hline $\mathrm{H} 28$ & $\begin{array}{l}\text { Head hitting raw material discharge line } \\
\text { or valve }\end{array}$ & Trauma, broken bones, cut & 3 & 6 & 3 & 54 & 33 \\
\hline $\mathrm{H} 29$ & $\begin{array}{l}\text { Using utility knife } \\
\text { Usenotitive }\end{array}$ & Cut in the skin, limb loss & 3 & 6 & 15 & 270 & 25 \\
\hline H30 & $\begin{array}{l}\text { Ergonomically inconvenience (repetitive } \\
\text { movement, lifting load, } \\
\text { pushing-pulling) }\end{array}$ & $\begin{array}{l}\text { Musculoskeletal disorder, } \\
\text { occupational disease }\end{array}$ & 3 & 10 & 40 & 1200 & 2 \\
\hline H31 & Using a mixer for mixing chemicals & Injury, limb, or tissue loss & 3 & 10 & 7 & 210 & 28 \\
\hline H32 & $\begin{array}{l}\text { Ambient noise as a result of the } \\
\text { operation of machinery and equipment }\end{array}$ & $\begin{array}{l}\text { Occupational disease due to } \\
\text { hearing loss }\end{array}$ & 3 & 10 & 40 & 1200 & 2 \\
\hline H33 & Sampling operation & Injury, limb or tissue loss & 3 & 10 & 15 & 450 & 15 \\
\hline $\mathrm{H} 34$ & $\begin{array}{c}\text { Process of valve opening and closing } \\
\text { and connection }\end{array}$ & $\begin{array}{c}\text { Backache, } \\
\text { disablement }\end{array}$ & 3 & 6 & 40 & 720 & 7 \\
\hline H35 & Ungrounded boilers & Death, injury & 3 & 3 & 40 & 360 & 21 \\
\hline H36 & Wet and slippery ground & $\begin{array}{l}\text { Slip and fall, broken } \\
\text { bones, injury }\end{array}$ & 3 & 6 & 40 & 720 & 7 \\
\hline $\mathrm{H} 37$ & Chemical spills & Skin irritation, burns & 3 & 3 & 40 & 360 & 21 \\
\hline $\mathrm{H} 38$ & Space constraints & Injury, limb or tissue loss & 3 & 10 & 40 & 1200 & 2 \\
\hline H39 & The process of cleaning the mixer & Injury, limb or tissue loss & 3 & 6 & 40 & 720 & 7 \\
\hline $\mathrm{H} 40$ & Stretching the boiler & Injury, balance loss & 3 & 10 & 40 & 1200 & 2 \\
\hline $\mathrm{H} 41$ & Overturning or spilling raw material & Injury, disablement & 3 & 6 & 40 & 720 & 7 \\
\hline $\mathrm{H} 42$ & Electrical leakage & Death, disablement & 3 & 6 & 40 & 720 & 7 \\
\hline
\end{tabular}


Table 9. Expressing criteria related to hazards/alternatives in linguistic terms.

\begin{tabular}{ccccccccccccccc}
\hline & H1 & H2 & H3 & H4 & H5 & H6 & H7 & H8 & H9 & H10 & H11 & H12 & H13 & H14 \\
\hline P & MG & MG & F & F & F & MP & G & MG & F & G & MG & F & F & F \\
E & MG & MG & MG & G & G & MP & G & G & MG & G & MP & MP & MP & P \\
S & G & G & F & F & MG & G & G & G & G & F & F & G & G & G \\
\hline & H15 & H16 & H17 & H18 & H19 & H20 & H21 & H22 & H23 & H24 & H25 & H26 & H27 & H28 \\
\hline P & MG & MP & F & MG & MG & F & MP & MG & MG & MG & MG & MG & MG & MG \\
E & G & G & MG & G & G & G & MP & VG & VG & VG & VG & VG & VG & G \\
S & MG & G & MG & G & G & MG & G & MG & MG & MG & MG & G & MG & MP \\
\hline & H29 & H30 & H31 & H32 & H33 & H34 & H35 & H36 & H37 & H38 & H39 & H40 & H41 & H42 \\
\hline P & MG & MG & MG & MG & MG & MG & MG & MG & MG & MG & MG & MG & MG & MG \\
E & G & VG & VG & VG & VG & G & MG & G & MG & VG & G & VG & G & G \\
S & MG & G & F & G & MG & G & G & G & G & G & G & G & G & G \\
\hline
\end{tabular}

After the criteria (P, E, S) for each hazard were expressed with linguistic terms according to Table 4, the fuzzy decision matrix was created using fuzzy numbers corresponding to the linguistic terms. The graded mean integration representation method given in Equation (7) was used in the created matrix, and the best non-fuzzy performance values for each criterion were calculated. They are shown in Table 10.

Table 10. Defuzzified values of hazards/alternatives.

\begin{tabular}{|c|c|c|c|c|c|c|c|c|c|c|c|c|c|c|}
\hline & H1 & $\mathrm{H} 2$ & H3 & H4 & H5 & H6 & H7 & H8 & H9 & H10 & H11 & H12 & H13 & H14 \\
\hline $\mathbf{P}$ & 7.000 & 7.000 & 5.000 & 5.000 & 5.000 & 3.000 & 8.833 & 7.000 & 5.000 & 8.833 & 7.000 & 5.000 & 5.000 & 5.000 \\
\hline $\mathbf{E}$ & 7.000 & 7.000 & 7.000 & 8.833 & 8.833 & 3.000 & 8 & 8.833 & 7.000 & 8.833 & 3.000 & 3. & 3.000 & 1.167 \\
\hline \multirow[t]{2}{*}{$\mathbf{S}$} & 8.833 & 8.833 & 5.000 & 5.000 & 7.000 & 8.833 & 8.833 & 8.833 & 8.833 & 5.000 & 5.000 & 8.833 & 8.833 & 8.833 \\
\hline & H15 & H16 & H17 & H18 & H19 & H20 & H21 & H22 & $\mathrm{H} 23$ & H24 & H25 & H26 & H27 & $\mathrm{H} 28$ \\
\hline $\mathbf{P}$ & 7.00 & 3.0 & 5.000 & 7.0 & 7.000 & 5.000 & 3. & 7.000 & 7.000 & 00 & 7.000 & 00 & 7.000 & 7.000 \\
\hline E & 8.833 & 8.8 & 7.000 & 8.833 & 8.833 & 8.833 & 3.000 & 9.833 & 9.833 & 9.833 & 9.833 & 33 & 9.833 & 8.833 \\
\hline \multirow[t]{2}{*}{$S$} & 7.000 & 8.833 & 7.000 & 8.833 & 8.833 & 7.000 & 8.833 & 7.000 & 7.000 & 7.000 & 7.000 & 8.833 & 7.000 & 3.000 \\
\hline & H29 & H30 & H31 & H32 & H33 & H34 & H35 & H36 & H37 & H38 & H39 & $\mathrm{H} 40$ & H41 & H42 \\
\hline $\mathbf{P}$ & 7.000 & 7.000 & 7.000 & 7.000 & 7.000 & 7.000 & 7.000 & 7.000 & 7.000 & 7.000 & 7.000 & 7.000 & 7.000 & 7.000 \\
\hline $\mathbf{E}$ & 8.833 & 9.833 & 9.833 & 9.833 & 9.833 & 8.833 & 7.000 & 8.833 & 7.000 & 9.833 & 8.833 & 9.833 & 8.833 & 8.833 \\
\hline$S$ & 7.000 & 8.833 & 5.000 & 8.833 & 7.000 & 8.833 & 8.833 & 8.833 & 8.833 & 8.833 & 8.833 & 8.833 & 8.833 & 8.833 \\
\hline
\end{tabular}

Obtained defuzzified values were normalized using the f-SWARA method, and the criteria were weighted by 10 OHS experts. According to this process, possibility, exposure, and severity values were calculated as $0.196,0.284$, and 0.518 , respectively, as shown in Table 7 in the previous section. After the calculations of the weights of the criteria with the f-SWARA method, by using Equation (10), the normalized values of alternatives were obtained. These values are shown in Table 11.

Table 11. Normalized values of hazards/alternatives.

\begin{tabular}{lllllllllllllll}
\hline & H1 & H2 & H3 & H4 & H5 & H6 & H7 & H8 & H9 & H10 & H11 & H12 & H13 & H14 \\
\hline $\mathbf{P}$ & 0.005 & 0.005 & 0.004 & 0.004 & 0.004 & 0.002 & 0.006 & 0.005 & 0.004 & 0.006 & 0.005 & 0.004 & 0.004 & 0.004 \\
$\mathbf{E}$ & 0.006 & 0.006 & 0.006 & 0.008 & 0.008 & 0.003 & 0.008 & 0.008 & 0.006 & 0.008 & 0.003 & 0.003 & 0.003 & 0.001 \\
$\mathbf{S}$ & 0.014 & 0.014 & 0.008 & 0.008 & 0.011 & 0.014 & 0.014 & 0.014 & 0.014 & 0.008 & 0.008 & 0.014 & 0.014 & 0.014 \\
\hline & $\mathbf{H 1 5}$ & $\mathbf{H 1 6}$ & $\mathbf{H 1 7}$ & $\mathbf{H 1 8}$ & $\mathbf{H 1 9}$ & $\mathbf{H 2 0}$ & $\mathbf{H 2 1}$ & $\mathbf{H 2 2}$ & $\mathbf{H 2 3}$ & $\mathbf{H 2 4}$ & $\mathbf{H 2 5}$ & $\mathbf{H 2 6}$ & $\mathbf{H 2 7}$ & $\mathbf{H 2 8}$ \\
\hline $\mathbf{P}$ & $\mathbf{0 . 0 0 5}$ & 0.002 & 0.004 & 0.005 & 0.005 & 0.004 & 0.002 & 0.005 & 0.005 & 0.005 & 0.005 & 0.005 & 0.005 & 0.005 \\
$\mathbf{E}$ & 0.008 & 0.008 & 0.006 & 0.008 & 0.008 & 0.008 & 0.003 & 0.008 & 0.008 & 0.008 & 0.008 & 0.008 & 0.008 & 0.008 \\
$\mathbf{S}$ & $\mathbf{0 . 0 1 1}$ & 0.014 & 0.011 & 0.014 & 0.014 & 0.011 & 0.014 & 0.011 & 0.011 & 0.011 & 0.011 & 0.014 & 0.011 & 0.005 \\
\hline & $\mathbf{H 2 9}$ & $\mathbf{H 3 0}$ & $\mathbf{H 3 1}$ & $\mathbf{H 3 2}$ & $\mathbf{H 3 3}$ & $\mathbf{H 3 4}$ & $\mathbf{H 3 5}$ & $\mathbf{H 3 6}$ & $\mathbf{H 3 7}$ & $\mathbf{H 3 8}$ & $\mathbf{H 3 9}$ & $\mathbf{H 4 0}$ & $\mathbf{H 4 1}$ & $\mathbf{H 4 2}$ \\
\hline $\mathbf{P}$ & $\mathbf{0 . 0 0 5}$ & 0.005 & 0.005 & 0.005 & 0.005 & 0.005 & 0.005 & 0.005 & 0.005 & 0.005 & 0.005 & 0.005 & 0.005 & 0.005 \\
$\mathbf{E}$ & 0.008 & 0.008 & 0.008 & 0.008 & 0.008 & 0.008 & 0.006 & 0.008 & 0.006 & 0.008 & 0.008 & 0.008 & 0.008 & 0.008 \\
$\mathbf{S}$ & 0.011 & 0.014 & 0.008 & 0.014 & 0.011 & 0.014 & 0.014 & 0.014 & 0.014 & 0.014 & 0.014 & 0.014 & 0.014 & 0.014 \\
\hline
\end{tabular}


After the normalization of alternatives, $P_{i}$ and $R_{i}$ values were determined with the help of Equations (12) and (13). Since there was no benefit criterion, the $P_{i}$ value was zero for all the alternatives. According to the calculated $R_{i}$ values, the lowest score was the H11 alternative with $R_{\min }=0.016$. After the calculations, $\sum_{i=1}^{n} R_{i}=0.999$ and $\sum_{i=1}^{n} \frac{R_{\min }}{R_{i}}=28.236$ values were obtained. The ultimate values calculated using Equations (14)-(17) are given in Table 12. Furthermore, the rankings of the alternatives are given in Table 12. The alternatives are ranked from the most dangerous to the least dangerous in this table. Therefore, H11 with an $N_{i}$ value of 1.000 is in the 42nd row, and H7 with an $N_{i}$ value of 0.557 is in the 1 st row.

Table 12. Calculation and ranking of the $Q_{i}$ and $N_{i}$ values of te hazards/alternatives.

\begin{tabular}{|c|c|c|c|c|c|c|c|c|c|c|c|c|c|c|}
\hline & H1 & $\mathrm{H} 2$ & H3 & $\mathrm{H} 4$ & H5 & H6 & H7 & H8 & H9 & H10 & H11 & H12 & H13 & H14 \\
\hline$P_{i}$ & - & - & - & - & - & - & - & - & - & - & - & - & - & - \\
\hline$R_{i}$ & 0.025 & 0.025 & 0.018 & 0.019 & 0.022 & 0.019 & 0.028 & 0.027 & 0.024 & 0.022 & 0.016 & 0.020 & 0.020 & 0.019 \\
\hline$Q_{i}$ & 0.022 & 0.022 & 0.031 & 0.029 & 0.025 & 0.029 & 0.020 & 0.021 & 0.023 & 0.025 & 0.035 & 0.027 & 0.027 & 0.030 \\
\hline$\widehat{N}_{i}$ & 0.622 & 0.622 & 0.889 & 0.816 & 0.700 & 0.832 & 0.557 & 0.585 & 0.660 & 0.712 & 1.000 & 0.772 & 0.772 & 0.836 \\
\hline \multirow[t]{2}{*}{ Ranking } & 15 & 15 & 40 & 36 & 29 & 37 & 1 & 7 & 28 & 31 & 42 & 34 & 34 & 39 \\
\hline & H15 & H16 & H17 & H18 & H19 & H20 & H21 & H22 & H23 & H24 & H25 & H26 & H27 & H28 \\
\hline$P_{i}$ & - & - & - & - & - & - & - & - & - & - & - & - & - & - \\
\hline$R_{i}$ & 0.024 & 0.024 & 0.021 & 0.027 & 0.027 & 0.022 & 0.019 & 0.025 & 0.025 & 0.025 & 0.025 & 0.028 & 0.025 & 0.017 \\
\hline$Q_{i}$ & 0.023 & 0.023 & 0.027 & 0.021 & 0.021 & 0.025 & 0.029 & 0.022 & 0.022 & 0.022 & 0.022 & 0.020 & 0.022 & 0.032 \\
\hline$\widehat{N}_{i}$ & 0.657 & 0.657 & 0.753 & 0.585 & 0.585 & 0.700 & 0.832 & 0.634 & 0.634 & 0.634 & 0.634 & 0.567 & 0.634 & 0.896 \\
\hline \multirow[t]{2}{*}{ Ranking } & 25 & 27 & 33 & 7 & 7 & 29 & 37 & 19 & 19 & 19 & 19 & 2 & 19 & 41 \\
\hline & H29 & H30 & H31 & H32 & H33 & H34 & H35 & H36 & H37 & H38 & H39 & H40 & H41 & $\mathrm{H} 42$ \\
\hline$P_{i}$ & - & - & - & - & - & - & - & - & - & - & - & - & - & - \\
\hline$R_{i}$ & 0.024 & 0.028 & 0.021 & 0.028 & 0.025 & 0.027 & 0.025 & 0.027 & 0.025 & 0.028 & 0.027 & 0.028 & 0.027 & 0.027 \\
\hline$Q_{i}$ & 0.023 & 0.020 & 0.026 & 0.020 & 0.022 & 0.021 & 0.022 & 0.021 & 0.022 & 0.020 & 0.021 & 0.020 & 0.021 & 0.021 \\
\hline$\widehat{N}_{i}$ & 0.657 & 0.567 & 0.728 & 0.567 & 0.634 & 0.585 & 0.622 & 0.585 & 0.622 & 0.567 & 0.585 & 0.567 & 0.585 & 0.585 \\
\hline Ranking & 25 & 2 & 32 & 2 & 19 & 7 & 15 & 7 & 15 & 2 & 7 & 2 & 7 & 7 \\
\hline
\end{tabular}

The $N_{i}$ value for every alternative was calculated by COPRAS analysis. These values are given in Table 12 and Figure 3. In the calculated values, $\mathrm{H} 11$ with a $N_{i}$ value of 1 indicates the least dangerous situation. On the contrary, H7 with a $N_{i}$ value of 0.557 indicates the most dangerous situation. The priority for taking measures was determined for the alternatives/hazards between these values. The most dangerous hazard that should be dealt with immediately (H7) was in Cluster 1 only. The values in Table 13 were used for the determination of clusters, except for that containing H7. Clusters of the alternatives are shown in Figure 4.

Determining the precautions is an important step after the classification of hazards. Measures to be taken will be significantly helpful in eliminating or reducing risk. The suggested precautions for the hazards addressed in this study are given in Table 14 and are according to the legislation. The legislation includes (1) ISO 45001 Occupational Health and Safety Management Systems, (2) ISO 31000:2018 Risk Management Guidelines, and (3) Turkey's Occupational Health and Safety Law, numbered 6331, and its related regulations, such as (a) Risk Assessment for OHS, (b) Using Personal Protective Equipment in Workplaces, (c) Health and Safety Requirements for the [Use of] Work Equipment, (d) Procedures and Principles of OHS Training of Employees, (e) Health and Safety Precautions to be Taken in Workplace Buildings and Attachments, (f) Health and Safety Precautions in Working with Chemical Substances, (g) Health and Safety Signs, and (h) Vocational Training of Persons to be Employed in the Dangerous and Very Dangerous Classes. 


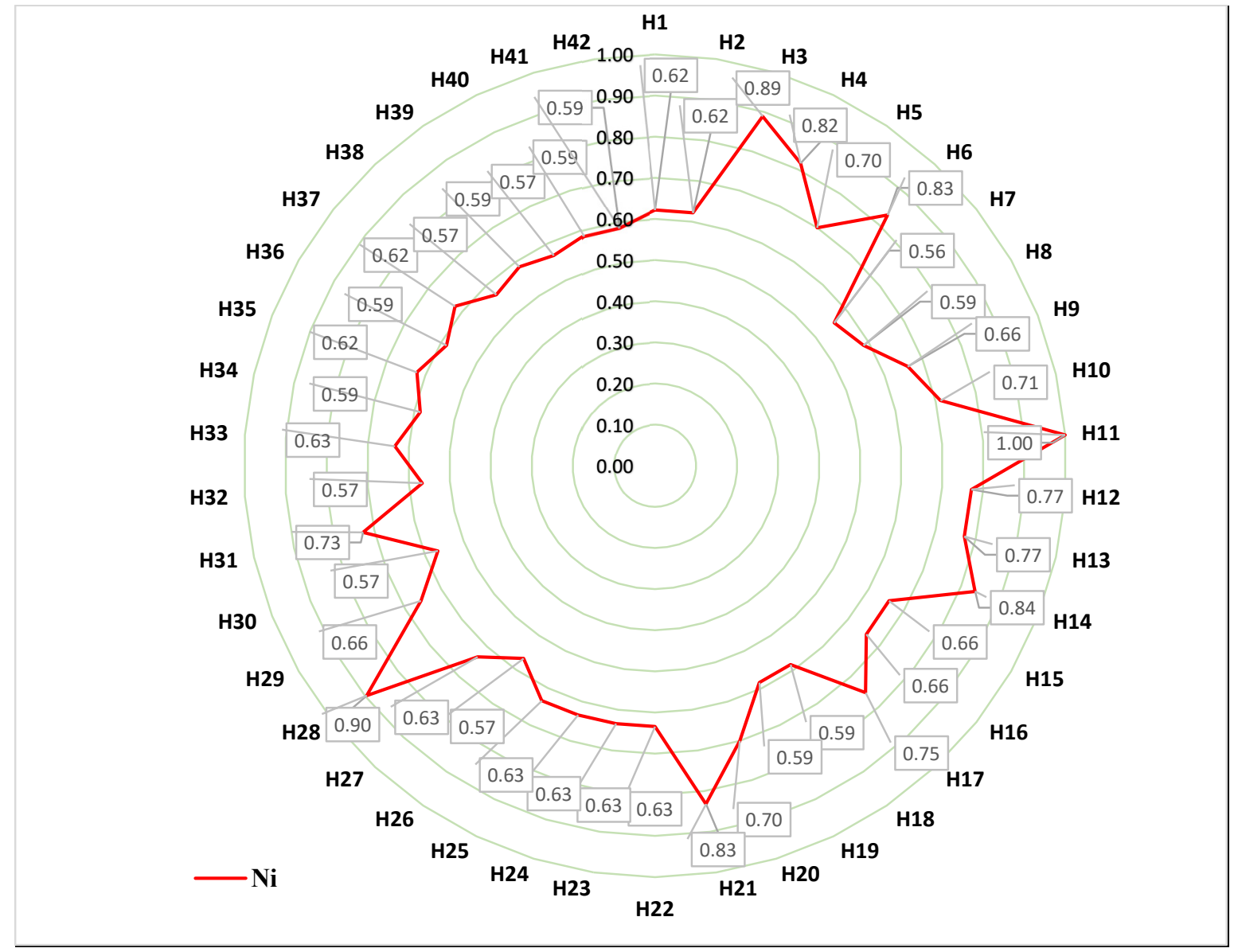

Figure 3. $N_{i}$ values of hazards/alternatives in the f-SC method.

Table 13. Risk clusters and the levels of the hazards/alternatives.

\begin{tabular}{ccl}
\hline Cluster No & $\boldsymbol{N}_{\boldsymbol{i}}$ Range & \multicolumn{1}{c}{ Risk Level } \\
\hline II & 0.557 & Very High Risk. Measures must be taken \\
III & $0.561-0.630$ & High Risk \\
Measures should be taken within 3 months.
\end{tabular}

As a result of the analysis performed with the f-SC method, the hazards are ranked in Table 12. A comparison of the hazard rankings obtained as a result of the classical Fine-Kinney method analysis, the f-VIKOR method analysis, and the f-SC method analysis is shown in Figure 5. In addition, the classes of hazards were determined for the f-SC, the classical Fine-Kinney, and f-VIKOR methods, and a comparison is shown in Figure 6. 


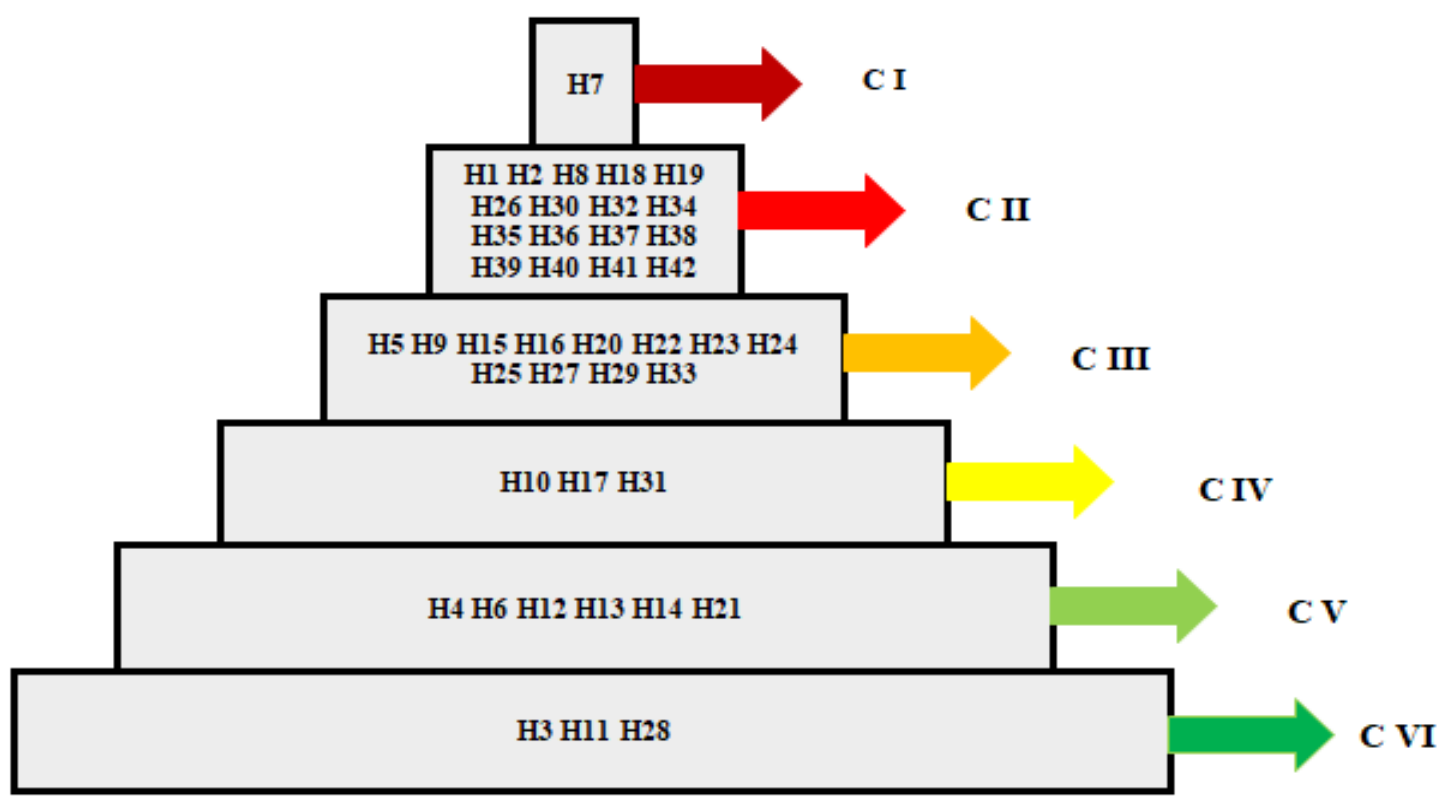

Figure 4. Risk clusters of the hazards/alternatives.

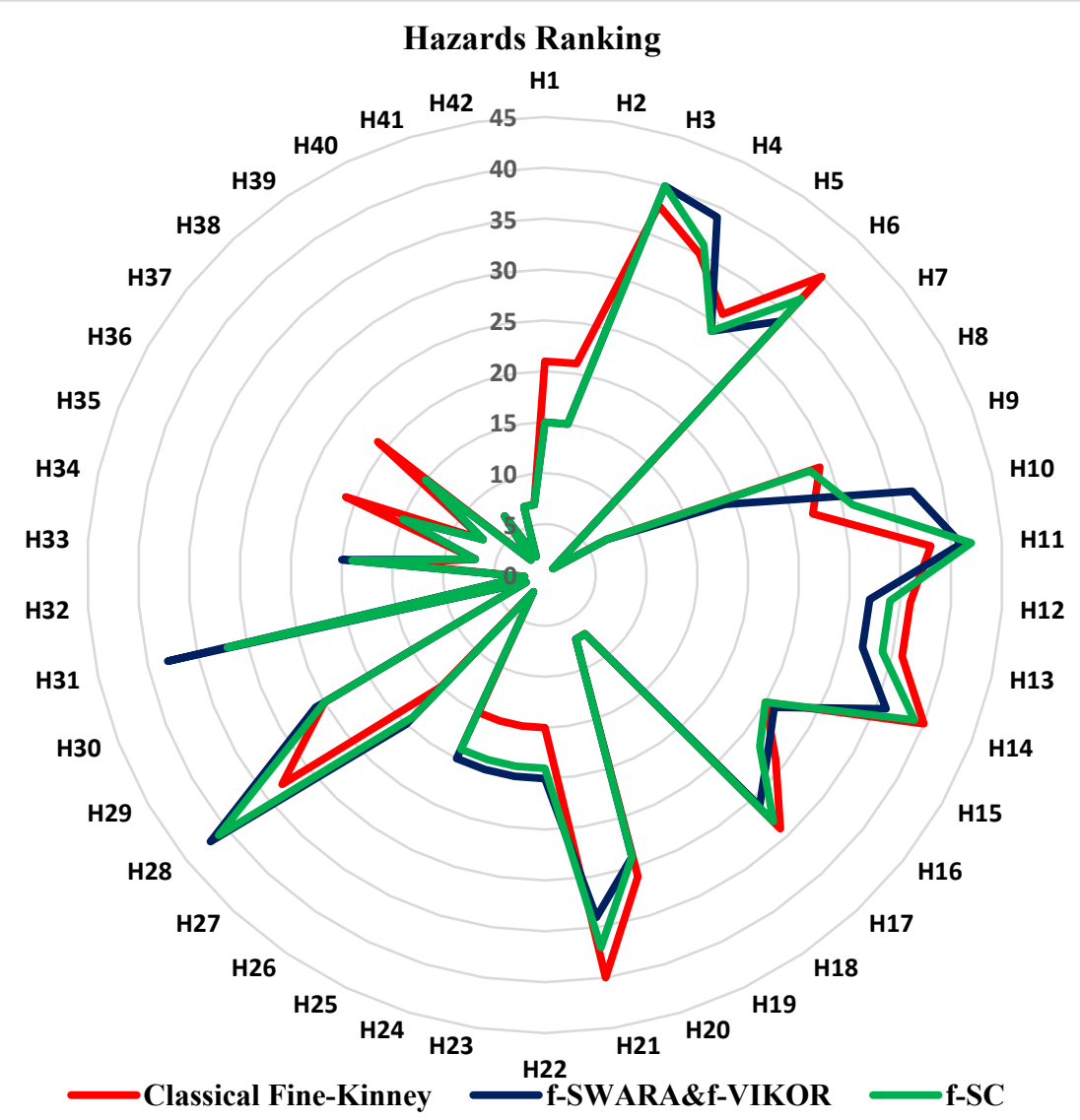

Figure 5. Comparison of the f-SC method with the classical Fine-Kinney and f-VIKOR methods in terms of the hazard rankings. 
Table 14. Precautions for the existing hazards.

\begin{tabular}{|c|c|c|}
\hline Hazard Number & Cluster Number & Precautions \\
\hline $\mathrm{H} 7$ & I & $\begin{array}{l}\text { - Seat belts and lifelines must be used when working at heights. } \\
\text { - The health and special education of the employees working at heights must be controlled. } \\
\text { Only those who have a work-at-height report can work at height. }\end{array}$ \\
\hline $\begin{array}{l}\mathrm{H} 1, \mathrm{H} 2, \mathrm{H} 8, \mathrm{H} 18, \mathrm{H} 19 \\
\text { H26, H30, H32, H34, } \\
\text { H35, H36, H37, H38, } \\
\text { H39, H40, H41, H42 }\end{array}$ & II & 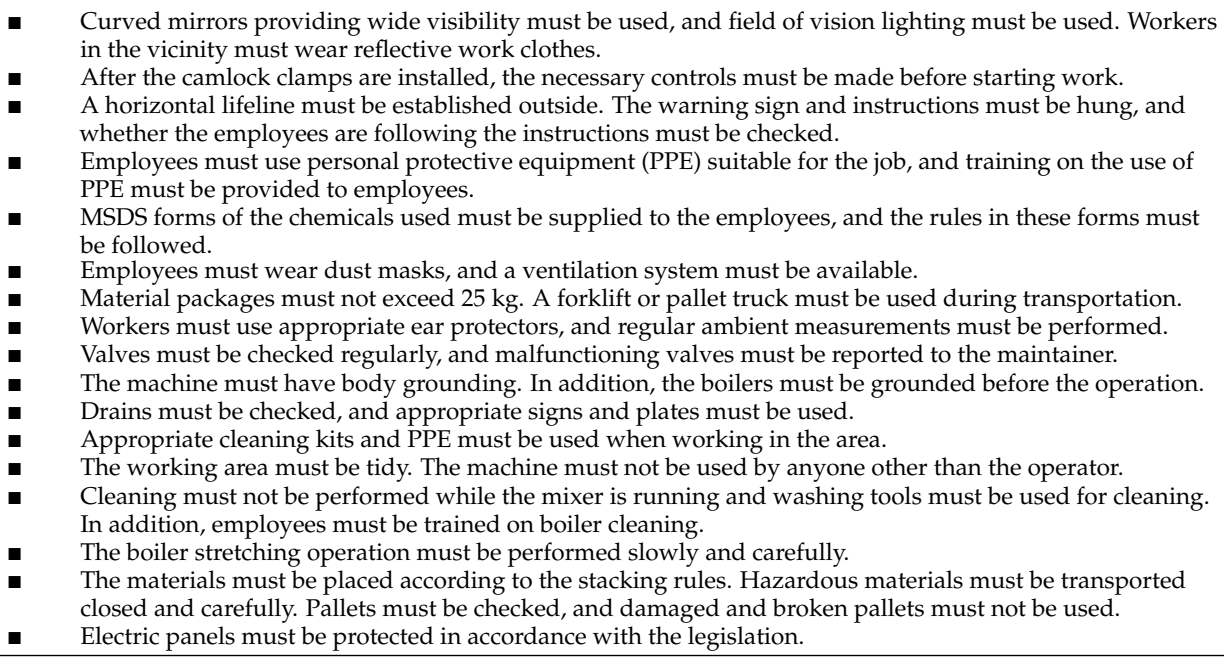 \\
\hline $\begin{array}{l}\text { H5, H9, H15, H16, } \\
\text { H20, H22, H23, H24, } \\
\text { H25, H27, H29, H33 }\end{array}$ & III & $\begin{array}{l}\text { - Silobas vehicles must be checked periodically, and pressure indicators and alarms in silos must be } \\
\text { monitored regularly. } \\
\text { - Pneumatic pumps must be fitted with a silencer. According to the noise measurement results, appropriate } \\
\text { PPE must be used in the required areas. } \\
\text { The maximum speed limit within the facility must be } 20 \mathrm{~km} / \mathrm{h} \text {, and all suppliers must be informed. In } \\
\text { addition, vehicles entering the facility must be in a certain order. } \\
\text { The grounding of the vehicles must be performed properly, and periodic checks must be provided. } \\
\text { - Employees must be given work clothes suitable for seasonal conditions. Cordless hand tools must be used. } \\
\text { - Boilers must be used with wheels. } \\
\text { - The filling line must have a suitable ventilation system, and the filling process must be performed with } \\
\text { hoses. In addition, appropriate PPE must be used to prevent exposure to workers. } \\
\text { - A scissor pallet truck must be used for lifting heavy materials. } \\
\text { - A safety utility knife must be used in all areas. } \\
\text { - The mixer must be stopped during the sampling process, and the bucket must be used during this process. }\end{array}$ \\
\hline H10, H17, H31 & IV & $\begin{array}{l}\text { - During the procedure, protective glasses must be used, work clothes must be worn, and hygiene rules } \\
\text { must be followed. } \\
\text { All vehicles entering the facility must have an exhaust protector (flame/spark arrester). Unoperated } \\
\text { vehicles must not be left running. } \\
\text { The boiler must be fixed with a seatbelt, and there must be an emergency stop button to cut energy in } \\
\text { an emergency. }\end{array}$ \\
\hline $\begin{array}{c}\mathrm{H} 4, \mathrm{H} 6, \mathrm{H} 12, \mathrm{H} 13, \\
\text { H14, H21 }\end{array}$ & V & $\begin{array}{l}\text { - Work clothes must be worn. PPE (half mask, work gloves, and work glasses) must be used. } \\
\text { Pressure gauges and alarms in silos must be checked regularly. In addition, periodic inspections of silobas } \\
\text { vehicles must be performed. } \\
\text { The driver must not be allowed to exit before the damper is closed. Periodic inspections must } \\
\text { be performed. } \\
\text { Inspection reports showing that the necessary periodic controls of the silos have been made must } \\
\text { be supplied. } \\
\text { - Materials on the roof must be fixed. }\end{array}$ \\
\hline H3, H11, H28 & VI & $\begin{array}{l}\text { The weight of the hoses must not exceed } 15 \mathrm{~kg} \text {. During insertion and removal, the pipes must be } \\
\text { transported by pulling them. } \\
\text { Maintenance and repair activities must be carried out periodically by the maintenance and repair team. } \\
\text { Employees must use helmets during work. }\end{array}$ \\
\hline
\end{tabular}

Figure 5 shows that, for all methods, the highest scored risk was Hazard 7 (H7). Moreover, the differences in the ranking of hazards can be seen in Figure 5.

When the hazard groups were examined, as shown in Figure 6, it can be seen that some hazard groups changed. This stage of the analysis was quite significant since it determined the timetable for the precautions. 


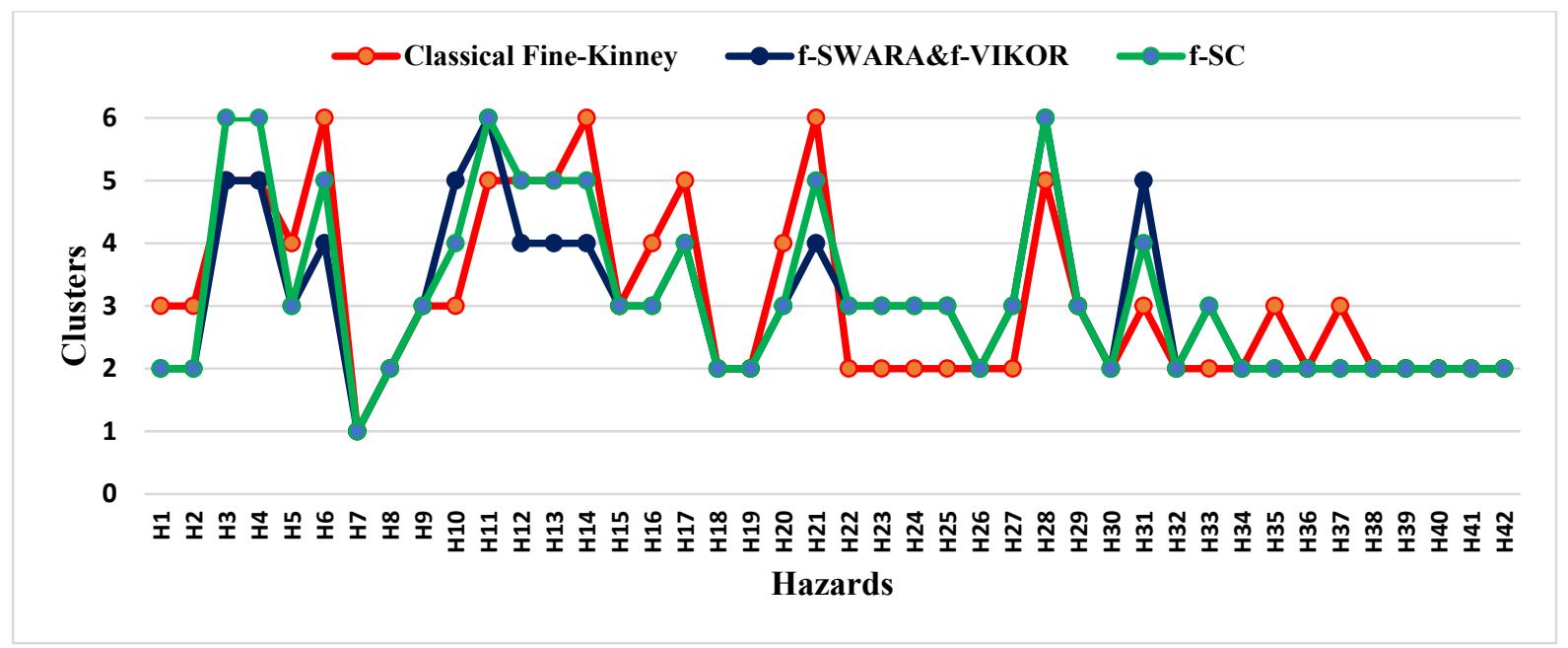

Figure 6. Comparison of the f-SC method with the classical Fine-Kinney and f-VIKOR methods in terms of the hazard groups.

\section{Discussion}

It is essential to determine the activities to be implemented in order to ensure the health and safety of the employees in the workplace. While determining these activities, it is necessary to analyze the working environments in detail, and the hazards that may pose risks in these environments should be identified accurately and completely. For this reason, the chosen risk analysis methods should be appropriate for the work.

Traditional risk models are based on probability and classical set theory. In these methods, risk analyses are made using numerical data. However, it may not always be easy to obtain numerical data in the workplace. In such cases, existing risks will need to be evaluated based on the opinions and judgments of experts (decision makers) instead of numerical data. Thus, fuzzy logic models can be used where assessments can be made with insufficient data. While hazards are prioritized as in classical risk analysis methods, a controversial result that may lead to different interpretations can be obtained. For instance, high probability and low severity hazards can be classified at the same level as low-probability and high-severity hazards. These problems can be eliminated by using fuzzy logic-based MCDM risk analysis methods. In this study, the novel hybrid f-SC risk analysis method was applied in a workplace, i.e., a water-based paint manufacturing area in the paint industry. A classical Fine-Kinney risk analysis was carried out for this particular workplace.

In classical methods, a risk score obtained with numerical values is given to each criterion when performing risk analysis. If applied to such cases, the impact rates of all criteria are assumed to be equal. However, not all criteria have the same level of importance. Hence, in this study, before the risk analysis was performed with the f-COPRAS method, with the help of the f-SWARA method, 10 OHS experts were used as decision makers to weight the criteria. As a result of the study, the weights of probability, exposure, and severity criteria were determined as $0.196,0.285$, and 0.518 , respectively.

Forty-two hazards were used as an alternative for the analysis and the criteria (P, E, and S) were weighted with the help of the f-SWARA method. $N_{i}$ values were then determined for each alternative using the relevant calculations of the f-COPRAS method. Since none of the criteria we used in our study were benefit criteria, this value was evaluated as " 0 ". The f-COPRAS analysis makes a benefit-oriented ranking while listing the alternatives. In other words, the alternative with an $N_{i}$ value of 1 , in the range of $0-1$, is most useful. In this context, a smaller $N_{i}$ value corresponding to the risk score calculated for each alternative/hazard by the integrated method means a greater risk. As a result of the study, $\mathrm{H} 7$ corresponded to the most dangerous situation since it had the smallest $N_{i}$ value (0.557). On the other hand, H11, which had a value of 1 , was the least dangerous situation. 
After the risk analysis was completed, timetables for the necessary precautions were identified according to the classification, and the necessary precautions are given in Table 14 according to related standards and regulations. Health and safety precautions should be classified carefully and conducted on time; otherwise, great losses are likely to occur.

As a result of the analysis made within the scope of the study, different classifications were obtained for the classical Fine-Kinney method and the novel hybrid f-SC method combining the f-SWARA and f- COPRAS MCDM methods, since the criteria, without any weighting, do not have sensitivity and certainty in the classical Fine-Kinney method. With the new hybrid f-SC method, using MCDM methods based on fuzzy logic, the criteria were weighted, and the sensitivity was increased. Thus, the uncertainties of the classical Fine-Kinney method were minimized. There were differences between the risk classes arising from hazards in these two methods. Moreover, analyses were conducted with the f-VIKOR method, which has been used in previous studies for risk analysis in the field of $\mathrm{OHS}$ using existing data. In the analyses, the same criteria weighting values of the f-SC method were used. Using the results obtained from these analyses, a triple comparison was made. The results of the f-VIKOR method, which have been accepted in the literature, and the new hybrid f-SC method of this study were parallel to each other.

\section{Conclusions}

A decision-making process is needed for the determination of risks in the workplace. For this reason, our new hybrid f-SC multi-criteria decision-making method is suitable. Using MCDM methods based on fuzzy logic is more suitable since, compared to numerical values, linguistic terms are easier to understand. Thus, in this paper, considerable efforts were made to eliminate the uncertainties and lack of sensitivity of classical methods.

In this study, we used 42 hazards of a particular department in a chosen workplace for our proposed risk analysis method. It was chosen and limited in this way because increasing the number of alternatives causes additional mathematical operations for decision makers and causes difficulties in presenting the data. However, a risk analysis should be made in detail for any company to take significant precautions. In future work, the f-SC method can be used for risk analyses in other industries. Alternatives can be multiplied using different MCDM methods for risk analyses, and comparisons can thus be made with different methods for criterion weighting. In addition, an application can be developed for the novel f-SC method for use by OHS experts in various workplaces.

The results showed that all the criteria had different levels of importance in terms of the risk score, and changes in risk prioritizing and risk clusters can be made by weighting the criteria. It is easier for decision makers to score criteria when linguistic terms are used instead of numerical values. The case study made in this study indicated that using our proposed approach instead of the conventional method increases accuracy and sensitivity in risk analyses. Furthermore, similar results were obtained by applying the f-VIKOR method, a method that has been used in the literature, alongside our proposed approach, which demonstrates the validity of our study.

This paper provides four critical contributions to classical risk analysis methods: (1) unlike the traditional Fine-Kinney method, OHS experts weighted the criteria before the risk analysis in the proposed f-SC method. This changed the risk scores and their risk clusters; (2) OHS experts, independent from each other, considered linguistic terms, which made the valuing of the criteria more consistent and reliable; (3) By using the proposed method, hazards were analyzed and ranked accurately and with sensitivity; (4) The classical Fine-Kinney method was chosen in this study since it is widely used in the vast majority of industries in Turkey. The f-SC method eliminates the shortcomings and disadvantages of the classical Fine-Kinney method. 
Author Contributions: Conceptualization, S.E.H. and H.T.; methodology, S.E.H. and H.T.; software, S.E.H.; validation, S.E.H., B.M. and H.T.; formal analysis, S.E.H.; investigation, S.E.H.; resources, S.E.H., B.M. and H.T.; data curation, S.E.H.; writing-original draft preparation, S.E.H.; writing-review and editing, S.E.H., B.M. and H.T.; visualization, S.E.H., B.M. and H.T.; supervision, B.M. and H.T. All authors have read and agreed to the published version of the manuscript.

Funding: This research received no external funding.

Institutional Review Board Statement: Ethical review and approval were waived for this study because it was not required. The data is not considered to be sensitive or confidential in nature. Vulnerable or dependent groups were not included. The subject matter was limited to topics that are strictly within the professional competence of the participants.

Informed Consent Statement: Informed consent was obtained from all subjects involved in the study.

Data Availability Statement: We will review the request to provide data to readers once is required.

Conflicts of Interest: The authors declare that they have no conflict of interests.

\section{References}

1. Moatari-Kazerouni, A.; Chinniah, Y.; Agard, B. A proposed occupational health and safety risk estimation tool for manufacturing systems. Int. J. Prod. Res. 2014, 53, 4459-4475. [CrossRef]

2. Health and Safety Executive. U.K. Risk Assessment: A Brief Guide to Controlling Risks in the Workplace. 2014. Available online: https: / / www.hse.gov.uk/pUbns/indg163.pdf (accessed on 7 October 2021).

3. Gul, M.; Guven, B.; Guneri, A.F. A new Fine-Kinney-based risk assessment framework using FAHP-FVIKOR incorporation. J. Loss Prev. Process Ind. 2018, 53, 3-16. [CrossRef]

4. Kutlu, A.C.; Ekmekçioğlu, M. Fuzzy failure modes and effects analysis by using fuzzy TOPSIS-based fuzzy AHP. Expert Syst. Appl. 2012, 39, 61-67. [CrossRef]

5. Wang, W.; Liu, X.; Qin, Y. A fuzzy Fine-Kinney-based risk evaluation approach with extended MULTIMOORA method based on Choquet integral. Comput. Ind. Eng. 2018, 125, 111-123. [CrossRef]

6. Mangeli, M.; Shahraki, A.; Saljooghi, F.H. Improvement of risk assessment in the FMEA using nonlinear model, revised fuzzy TOPSIS, and support vector machine. Int. J. Ind. Ergon. 2019, 69, 209-216. [CrossRef]

7. Stanujkic, D.; Karabasevic, E.; Zavadskas, K. A Framework for the Selection of a Packaging Design Based on the SWARA Method. Inz. Ekon. Eng. Econ. 2015, 26, 181-187.

8. Zolfani, S.H.; Yazdani, M.; Zavadskas, E.K. An extended stepwise weight assessment ratio analysis (SWARA) method for improving criteria prioritization process. Soft Comput. 2018, 22, 7399-7405. [CrossRef]

9. Ruzgys, A.; Volvaciovas, R.; Ignatavicius, C.; Turkskis, Z. Integrated evaluation of external wall insulation in residential buildings using SWARA-TODIM MCDM method. J. Civ. Eng. Manag. 2014, 20, 103-110. [CrossRef]

10. Yucenur, G.N.; Caylak, S.; Gönül, G.; Postalcioglu, M. An integrated solution with SWARA\&COPRAS methods in renewable energy production: City selection for biogas facility. Renew. Energy 2020, 145, 2587-2597. [CrossRef]

11. Yazdani, M.; Alidoosti, A.; Zavadskas, E.K. Risk Analysis of Critical Infrastructures Using Fuzzy Copras. Econ. Res. Ekon. Istraž. 2011, 24, 27-40. [CrossRef]

12. Mulliner, E.; Smallbone, K.; Maliene, V. An assessment of sustainable housing affordability using a multiple criteria decision making method. Omega 2013, 41, 270-279. [CrossRef]

13. Wang, Y.; Xie, M. Approach to Integrate Fuzzy Fault Tree with Bayesian Network. Procedia Eng. 2012, 45, 131-138. [CrossRef]

14. Wang, D.; Zhang, P.; Chen, L. Fuzzy fault tree analysis for fire and explosion of crude oil tanks. J. Loss Prev. Process Ind. 2013, 26, 1390-1398. [CrossRef]

15. Kou, G.; Peng, Y.; Wang, G. Evaluation of clustering algorithms for financial risk analysis using MCDM methods. Inf. Sci. 2014, 275, 1-12. [CrossRef]

16. Liu, Y.; Yuan, Y.; Fan, Z.-P. A FTA-Based Method for Risk Decision Making in Emergency Response. Comput. Oper. Res. 2014, 42, 49-57. [CrossRef]

17. Lavasani, S.M.; Ramzali, N.; Sabzalipour, F.; Akyuz, E. Utilisation of Fuzzy Fault Tree Analysis (FFTA) for quantified risk analysis of leakage in abandoned oil and natural-gas wells. Ocean Eng. 2015, 108, 729-737. [CrossRef]

18. Rajakarunakaran, S.; Kumar, A.M.; Prabhu, V.A. Applications of fuzzy faulty tree analysis and expert elicitation for evaluation of risks in LPG refuelling station. J. Loss Prev. Process Ind. 2015, 33, 109-123. [CrossRef]

19. Guneri, A.F.; Gul, M.; Senim, O. A fuzzy AHP methodology for selection of risk assessment methods in occupational safety. Int. J. Risk Assess. Manag. 2015, 18, 319-335. [CrossRef]

20. Othman, M.R.; Idris, R.; Hassim, M.H.; Ibrahim, W.H.W. Prioritizing HAZOP analysis using analytic hierarchy process (AHP). Clean Technol. Environ. Policy 2016, 18, 1345-1360. [CrossRef]

21. Dağsuyu, C.; Göçmen, E.; Narlı, M.; Kokangül, A. Classical and fuzzy FMEA risk analysis in a sterilization unit. Comput. Ind. Eng. 2016, 101, 286-294. [CrossRef] 
22. Gul, M.; Celik, E. Fuzzy rule-based Fine-Kinney risk assessment approach for rail transportation systems. Hum. Ecol. Risk Assess. Int. J. 2018, 24, 1786-1812. [CrossRef]

23. Kokangül, A.; Polat, U.; Dağsuyu, C. A new approximation for risk assessment using the AHP and Fine Kinney methodologies. Saf. Sci. 2017, 91, 24-32. [CrossRef]

24. Yazdi, M.; Kabir, S. A fuzzy Bayesian network approach for risk analysis in process industries. Process Saf. Environ. Prot. 2017, 111, 507-519. [CrossRef]

25. Gul, M.; Ak, M.F. A comparative outline for quantifying risk ratings in occupational health and safety risk assessment. J. Clean. Prod. 2018, 196, 653-664. [CrossRef]

26. Fattahi, R.; Khalilzadeh, M. Risk evaluation using a novel hybrid method based on FMEA, extended MULTIMOORA, and AHP methods under fuzzy environment. Saf. Sci. 2018, 102, 290-300. [CrossRef]

27. Gul, M. A review of occupational health and safety risk assessment approaches based on multi-criteria decision-making methods and their fuzzy versions. Hum. Ecol. Risk Assess. Int. J. 2018, 24, 1723-1760. [CrossRef]

28. Markowski, A.S.; Siuta, D. Fuzzy logic approach for identifying representative accident scenarios. J. Loss Prev. Process Ind. 2018, 56, 414-423. [CrossRef]

29. Chen, K.; Liu, D.; Fan, Z.; Chen, X.; Khan, F. Risk Analysis of Oilfield Gathering Station. Process Saf. Prog. 2019, 38, 71-77. [CrossRef]

30. Simić, V.; Soušek, R.; Jovčić, S. Picture Fuzzy MCDM Approach for Risk Assessment of Railway Infrastructure. Mathematics 2020, 8, 2259. [CrossRef]

31. Marhavilas, P.K.; Tegas, M.G.; Koulinas, G.K.; Koulouriotis, D.E. A Joint Stochastic/Deterministic Process with Multi-Objective Decision Making Risk-Assessment Framework for Sustainable Constructions Engineering Projects-A Case Study. Sustainability 2020, 12, 4280. [CrossRef]

32. Marhavilas, P.K.; Filippidis, M.; Koulinas, G.K.; Koulouriotis, D.E. An expanded HAZOP-study with fuzzy-AHP (XPA-HAZOP technique): Application in a sour crude-oil processing plant. Saf. Sci. 2020, 124, 104590. [CrossRef]

33. Marhavilas, P.K.; Filippidis, M.; Koulinas, G.K.; Koulouriotis, D.E. A HAZOP with MCDM Based Risk-Assessment Approach: Focusing on the Deviations with Economic/Health/Environmental Impacts in a Process Industry. Sustainability 2020, 12, 993. [CrossRef]

34. Shahri, M.M.; Jahromi, A.E.; Houshmand, M. Failure Mode and Effect Analysis using an integrated approach of clustering and MCDM under pythagorean fuzzy environment. J. Loss Prev. Process Ind. 2021, 72, 104591. [CrossRef]

35. Boral, S.; Chakraborty, S. Failure analysis of CNC machines due to human errors: An integrated IT2F-MCDM-based FMEA approach. Eng. Fail. Anal. 2021, 130, 105768. [CrossRef]

36. Tabatabaee, S.; Mahdiyar, A.; Ismail, S. Towards the success of Building Information Modelling implementation: A fuzzy-based MCDM risk assessment tool. J. Build. Eng. 2021, 43, 103117. [CrossRef]

37. Wang, Z.-C.; Ran, Y.; Chen, Y.; Yang, X.; Zhang, G. Group risk assessment in failure mode and effects analysis using a hybrid probabilistic hesitant fuzzy linguistic MCDM method. Expert Syst. Appl. 2022, 188, 116013. [CrossRef]

38. Kinney, G.F.; Wiruth, A.D. Practical Risk Analysis for Safety Management; Final Report; Naval Weapons Center: Kern County, CA, USA, 1976.

39. Zadeh, L.A. Fuzzy Sets. Inf. Control 1965, 8, 338-353. [CrossRef]

40. Yong, D. Plant location selection based on fuzzy TOPSIS. Int. J. Adv. Manuf. Technol. 2006, 28, 839-844. [CrossRef] 